\title{
PIXEL-BASED CALIBRATION AND ATMOSPHERIC CORRECTION OF A UAS-MOUNTED THERMAL CAMERA FOR LAND SURFACE TEMPERATURE MEASUREMENTS
}

\author{
Yan Zhu' ${ }^{1, *}$, Keith Cherkauer ${ }^{1}$ \\ ${ }^{1}$ Department of Agricultural and Biological Engineering, Purdue University, West Lafayette, Indiana, USA. \\ *Correspondence: zhu631@purdue.edu,09zhuyan@gmail.com.
}

\section{Highlights}

- A novel pixel-based calibration algorithm and an atmospheric correction method are developed.

- Application of the calibration methods reduces the RMSE of measurements to less than $1.32^{\circ} \mathrm{C}$.

- The calibrations facilitate stitching of images together to form whole-field mosaics.

\begin{abstract}
Thermal imagery can be used to provide insight into the water stress status and evapotranspiration demand of crops, but satellite-based sensors are generally too coarse spatially and too infrequent temporally to provide information of use for the management of specific fields. Thermal cameras mounted on small unmanned aerial systems (UAS) have potential to provide canopy temperature information at high spatial and temporal resolutions useful for crop management; however, without appropriate camera corrections, the measurement biases of these uncooled thermal cameras can be larger than $\pm 5^{\circ} \mathrm{C}$. Such uncertainty can render such camera measurements useless. In this research, a pixel-based (non-uniformity) calibration algorithm and an atmospheric correction method based on in-field approximate blackbody sources (water targets) were developed for a thermal camera. The objective was to improve the temperature measurement accuracy of the thermal camera on various land surfaces including soil and vegetation. With sufficient accuracy, temperature measurements can be used for the estimation of latent heat flux of field crops in the future. The thermal camera was first calibrated in a laboratory setting where the camera and environmental conditions were controlled. The results indicated that in the range between $10^{\circ} \mathrm{C}$ and $45^{\circ} \mathrm{C}$, the calibrated temperatures were accurate, with an average bias of $1.76^{\circ} \mathrm{C}$, and had a high linear correlation with reference temperatures (water target temperatures) $\left(R^{2}>0.99\right)$. Variability of measurements was also better constrained. In-field atmospheric correction is also important for obtaining high-accuracy thermal imagery. By applying both pixel-based calibration and atmospheric corrections, the RMSE (root mean square error) of validation targets from two dates in 2017 was reduced from $4.56^{\circ} \mathrm{C}$ and $6.36^{\circ} \mathrm{C}$ before calibration to $1.32^{\circ} \mathrm{C}$ and $1.24^{\circ} \mathrm{C}$ after calibration. The calibration process also increased the range of temperatures in the imagery, which enhanced contrast and may help with identification of tie-points and stitching of images together to form whole-field mosaics.
\end{abstract}

Keywords. Atmospheric correction, Pixel-based calibration, Thermal remote sensing, UAS, Water targets.

$\mathrm{T}$ hermography is a non-invasive, non-contact, and non-destructive technique used to determine the thermal properties and features of any object of interest and therefore has potential use in agriculture (Ishimwe et al., 2014). It has been successfully applied to, but not limited to, nursery and greenhouse monitoring (Kranner et al., 2010; Eitel et al., 2010), irrigation scheduling (Osroosh et al., 2015; Gowda et al., 2008; Barbagallo et al., 2009), plant disease detection (Mahlein et al., 2012), crop yield estimation (Smith et al., 1985; Stajnko et al., 2004), soil texture mapping

\footnotetext{
cc) $(1) \fallingdotseq$ The authors have paid for open access for this article. This work is licensed under a Creative Commons AttributionNonCommercial-NoDerivatives 4.0 International License https://creative commons.org/licenses/by-nc-nd/4.0/

Submitted for review on 10 April 2021 as manuscript number MS 14631; approved for publication as a Research Article and as part of the UAVs in Agriculture Collection by the Information Technology, Sensors, \& Control Systems Community of ASABE on 28 September 2021.
}

(Wang et al., 2012), residue cover and tillage mapping (Kozak et al., 2007), soil salinity detection, evaluating maturity of crops and bruise detection in fruits and vegetables (Khanal et al., 2017; Scotford and Miller, 2004; Pen et al., 1985), and estimation of transpiration and stomatal conductance (Hoffmann et al., 2016; Ortega-Farías et al., 2016; Sepúlveda-Reyes et al., 2016; Berni et al., 2009a).

Before the advent of small unmanned aerial systems (UAS), satellite thermal sensors or cameras were the most common methods used to obtain thermal feature information of ground objects. However, their repeat times and spatial resolutions are not suitable for many applications in agricultural research that require sub-meter resolution and multiple observations at specific times of day (Cherkauer et al., 2005).

Currently, thermal cameras can be classified into two categories: uncooled and cooled. Uncooled thermal cameras are used on UAS because of their small size, light weight, and affordable price. Due to the lack of cooling components, 
they have slower image capture rates and are less sensitive than cooled cameras to differences in temperature within their field of view. Ribeiro-Gomes et al. (2017) and Budzier and Gerlach (2015) identified five types of calibration that should be conducted for a typical uncooled thermal camera: non-uniformity correction, defective pixel correction, shutter correction, radiometric calibration, and temperature dependence correction. For modern thermal cameras, defective pixel correction and shutter correction are generally integrated into the firmware included in the system. Temperature dependence correction can be reduced by bringing cameras to equilibrium with the local environment before data collection and operating them at a constant environmental temperature. That leaves users to address non-uniformity correction and radiometric calibration.

Many studies have focused on laboratory calibration of uncooled thermal cameras (e.g., Perry and Dereniak, 1993; Orżanowski, 2016; Sosnowski et al., 2010; Nugent et al., 2013; Ribeiro-Gomes et al., 2017). For example, Perry and Dereniak (1993) proposed a two-point correction method in which two separate calibration temperatures were used to remove additive and multiplicative nonuniformities from the sensor output. They found that the residual spatial noise was reduced from above $0.2^{\circ} \mathrm{C}$ to below $0.05^{\circ} \mathrm{C}$ compared to using only one calibration temperature; however, they assumed that the camera response to a wide range of temperatures would be linear, which cannot be assumed for uncooled cameras (Ribeiro-Gomes et al., 2017). Nugent et al. (2013) described a method for stabilizing a thermal camera's response based on the difference between the camera's response at a measured temperature and at a reference temperature. They reported a maximum error of $0.75^{\circ} \mathrm{C}$ after calibration for a thermal camera with initial uncertainty of $\pm 2{ }^{\circ} \mathrm{C}$. More recently, Ribeiro-Gomes et al. (2017) developed a calibration algorithm based on artificial neural networks for an uncooled thermal camera in a laboratory. Inputs for the algorithm include sensor temperature and digital response of the microbolometer. They reported that the measurement bias was reduced from $3.55^{\circ} \mathrm{C}$ with the original camera configuration to $1.37^{\circ} \mathrm{C}$ after calibration.

For field calibration, Lillesand et al. (2014) summarized the two most commonly used radiometric calibration methods for thermal infrared sensors: internal blackbody source referencing and air-to-ground calibration. The first method takes the form of two temperature-controlled ("hot" and "cold") blackbody radiation sources positioned near the camera in a place where they are viewed by the sensor periodically during flight. By comparing the signal recorded from the Earth's surface to the radiation from these two precisely controlled blackbody calibration sources, a mathematical relationship can be established to calibrate the sensor. This method does not account for atmospheric effects; however, because the blackbodies are positioned near the camera, there is little impact from atmospheric conditions. The other radiometric calibration method, air-to-ground calibration, can be used to correct for atmospheric effects. Observations are typically made at points where temperature is assumed to be constant. The corresponding scanner output value is then determined for each point of the ground-based surface temperature measurements. A calibration curve is then constructed relating the scanned output values to the corresponding ground-based radiant temperature.

Young et al. (2002) developed a method for atmospheric compensation of thermal hyperspectral data. They analyzed coarse-resolution satellite imagery from a hyperspectral camera, and the emissivity of all ground features was assumed to be unity. Spectral radiance emitted from the ground was approximated at a fixed reference spectral channel (a particular wavelength) where the maximum value of brightness temperature occurred. They demonstrated the ability to effect an atmospheric compensation of thermal hyperspectral data using only the data collection itself.

Additionally, radiative transfer models such as MODTRAN (MODerate resolution atmospheric TRANsmission) are also used to compensate for atmospheric effects (Berni et al., 2009b; Kay et al., 2005; Handcock et al., 2006).

Laboratory calibrations and atmospheric corrections have been demonstrated previously in the literature, but so far there have been few applications of these methods to UASmounted thermal infrared cameras. The non-uniformity correction methods developed previously have used only two calibration temperatures and assumed that the response from the infrared focal plane array to a wide range of temperatures is linear, which may be problematic for the variety of lowcost uncooled thermal cameras currently being employed.

In this research, we built our own in-field approximate blackbody sources (water targets), which are affordable and easy to make, and used them to develop a straightforward method for performing laboratory and field calibrations of thermal infrared cameras. In the laboratory calibration, 22 different calibration temperatures (from $0^{\circ} \mathrm{C}$ to $50^{\circ} \mathrm{C}$ ) were applied to develop pixel-based calibration equations. The lab-calibrated camera was then used for field operations, and methods are presented to calibrate and correct selected raw images for atmospheric effects. Finally, an assessment of the accuracy of the calibrated surface temperatures captured during a series of UAS flights is presented.

The objective of this research is to demonstrate a method to improve the measurement accuracy and precision of a low-cost, uncooled thermal camera mounted on a UAS platform for various land surfaces including soil and vegetation.

\section{THERMAL INFRARED MEASUREMENT}

A FLIR Vue Pro R camera (FLIR Systems, Wilsonville, Ore.) was used for all data collection. This camera has a pixel resolution of $640 \times 512$ and a focal length of $19 \mathrm{~mm}$ with a field of view $32^{\circ} \times 26^{\circ}$. The camera is sensitive to spectral wavelengths from 7.5 to $13.5 \mu \mathrm{m}$, with a manufacturer-reported measurement accuracy of $\pm 5^{\circ} \mathrm{C}$ or $5 \%$ of reading in its operating temperature range $\left(-20^{\circ} \mathrm{C}\right.$ to $\left.+50^{\circ} \mathrm{C}\right)$.

The camera has a factory radiometric calibration that allows the image digital numbers to be converted to temperature. As with most sensors, calibration of the specific system under conditions similar to how it will be operated is critical for obtaining the most accurate data. For the FLIR camera, we conducted calibration experiments in the laboratory to quantify the absolute accuracy and the noise equivalent temperature difference (NETD) and then used in-field water 
bodies to conduct in-flight atmospheric corrections. Detailed methods for these calibration processes are provided in the following sections.

The radiance from each calibration target that arrives at the sensor can be described by the following equation (Barsi et al., 2003; Young et al., 2002):

$$
\begin{aligned}
L(\lambda) & =\varepsilon(\lambda) B_{\lambda}(T) \tau(\lambda)+L_{u}(\lambda) \\
& +[1-\varepsilon(\lambda)] L_{d}(\lambda) \tau(\lambda)
\end{aligned}
$$

where

$L(\lambda)=$ detected spectral radiance at wavelength $\lambda(\mathrm{m})$

$\left(\mathrm{W} \mathrm{m} \mathrm{m}^{-2} \mathrm{sr}^{-1} \mu \mathrm{m}^{-1}\right)$

$\varepsilon(\lambda)=$ surface emissivity

$\tau(\lambda)=$ atmospheric transmittance for the path between the surface and the sensor

$L_{u}(\lambda)=$ upwelling atmospheric radiance for the same path $\left(\mathrm{W} \mathrm{m} \mathrm{m}^{-2} \mathrm{sr}^{-1} \mu \mathrm{m}^{-1}\right)$

$L_{d}(\lambda)=$ hemispherical downwelling radiance from the entire sky $\left(\mathrm{W} \mathrm{m}^{-2} \mathrm{sr}^{-1} \mu \mathrm{m}^{-1}\right)$

$B_{\lambda}(T)=$ spectral radiance emitted from a blackbody with the same temperature as the target $\left(\mathrm{W} \mathrm{m}^{-2} \mathrm{sr}^{-1} \mu \mathrm{m}^{-1}\right)$.

The spectral radiance emitted by an object is estimated using the Planck function:

$$
B_{\lambda}(T)=\frac{c_{1} \lambda^{-5}}{\pi\left(e^{\frac{c_{2}}{\lambda T}}-1\right)}
$$

where $T$ is temperature $(\mathrm{K})$, and the constants are defined as $c_{1}=3.74 \times 10^{-16} \mathrm{~W} \mathrm{~m}^{2}$ and $c_{2}=1.45 \times 10^{-2} \mathrm{mK}$. When conducting atmospheric corrections, the calibration target temperature is assumed to be equal to the bulk water temperature because the target is well mixed.

At-sensor radiance recorded by the thermal camera is calibrated to the radiance emitted by the ground calibration targets, as calculated from equation 2. For the calibration process, equation 1 can be simplified by not considering the downwelling radiance from the entire sky (Young et al., 2002):

$$
L(\lambda)=\varepsilon(\lambda) B_{\lambda}(T) \tau(\lambda)+L_{u}(\lambda)
$$

There are now only two unknowns left: $\tau(\lambda)$ the atmospheric transmittance and $L_{u}(\lambda)$ the upwelling atmospheric radiance. Equation 3 is also now simplified into the form of a line. In this research, we use ground reference temperature measurements and can directly derive the emitted radiance and emissivity of the ground targets (water, paint, fabric, etc.). Because our thermal camera is sensitive to a wide spectral range, from 7.5 to $13.5 \mu \mathrm{m}$, integration of emitted spectral radiance over the full range was used for the purpose of calibration and temperature estimation. In practice, for the range of normal terrestrial temperatures, all bodies can be treated as gray bodies so that the emissivity of the targets is considered constant across the sensitive spectral range of the thermal camera.
To conduct both the laboratory-based and in-field calibrations of the thermal camera, we constructed three water targets (fig. 1). Each water target consists of a reservoir containing about $30 \mathrm{~L}$ of water shaded from direct sunlight. A pump pulls water from the reservoir and pushes it out into the middle of a circular pan. The pan is made of vinyl with a diameter of $43 \mathrm{~cm}$ to make sure it is visible in the thermal imagery. The depth of the water surface on top of the pan is about $5 \mathrm{~cm}$, and the height of the water target is $60 \mathrm{~cm}$. Water pumped into the pan flows from the center to the edge, where it falls back into the reservoir. By continually moving the water visible to the UAS sensor, the water target minimizes the formation of a cooler skin layer on the surface of the water. This process means that the water surface is constantly being refreshed, so emissions in the thermal infrared reflect the bulk temperature of the water rather than the cooler skin temperature that forms from evaporation (Kay et al., 2005). Because we use tap water for the targets, the thermal emissivity of water is assumed to be 0.98 (Campbell and Norman, 2012).

One resistance temperature detector (RTD, Omega Engineering, Stamford, Conn.) with an accuracy of $\pm 0.2^{\circ} \mathrm{C}$ was deployed in the reservoir of each target and used to

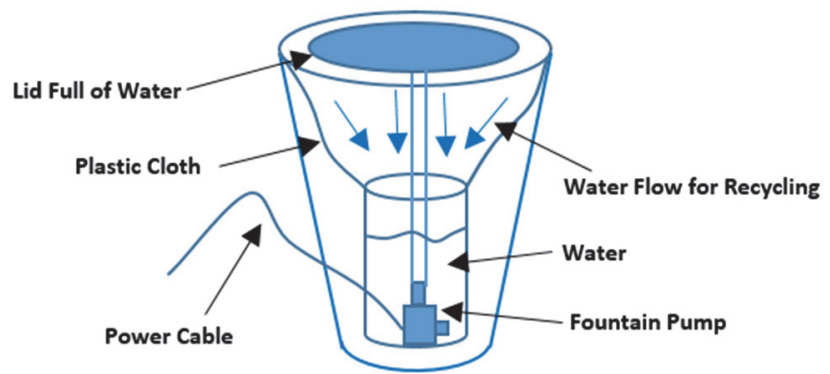

(a)

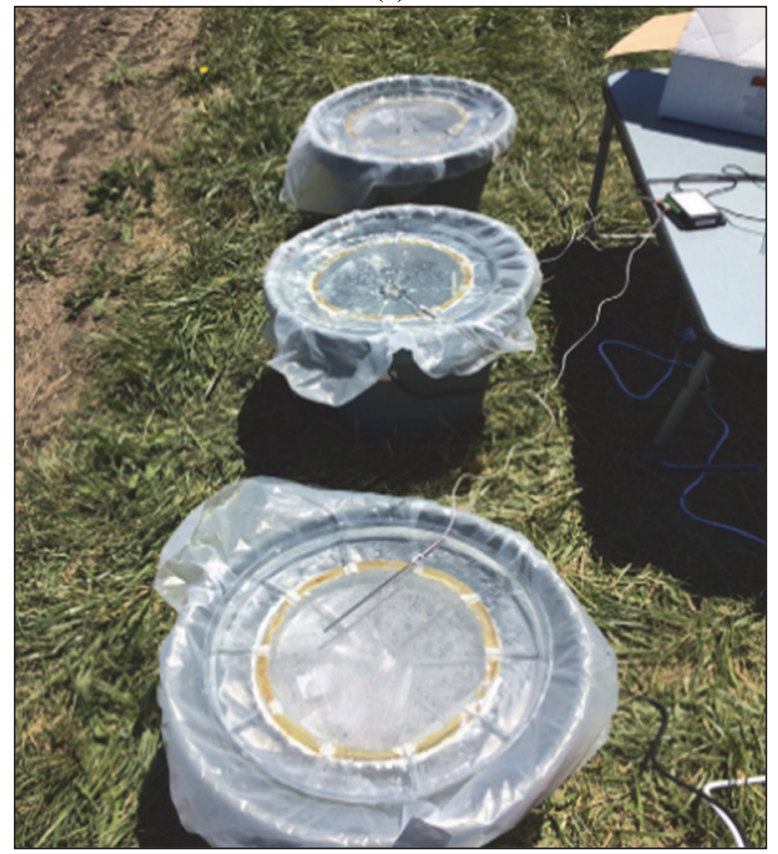

(b)

Figure 1. (a) Schematic of a water target and (b) photo of water targets deployed in the field during flight operations. 
continuously measure the bulk water temperature during calibration operations. The targets provide a range of temperatures for calibration, with the temperatures of the warm and cool water selected to ensure that the temperatures of all objects in the field of view fall within this range. This means that we only need to interpolate the temperature information of unknown pixels, instead of extrapolating it, which makes the calibration more accurate.

\section{LABORATORY-BASED CALIBRATION}

The thermal camera and all other temperature sensors used during field operations were first calibrated in a laboratory setting where the camera and environmental conditions could be controlled. The temperature of the laboratory during calibrations was $25^{\circ} \mathrm{C}$. The NETD of the camera was then quantified.

\section{Accuracy of Thermal Camera and Other Temperature Sensors}

The camera is composed of $640 \times 512$ detectors. Because each pixel value reflects the radiance it detects, we correlated the pixel values (digital numbers) with the emitted radiance from a water target such that we optimized the measurements of the thermal camera. Absolute accuracy was calibrated against a high-accuracy NIST-certified temperature sensor across a range of water temperatures.

Laboratory calibration was conducted using a single water target to provide a well-mixed water body and an effective approximate blackbody. The thermal camera was allowed to warm up by turning it on about 20 min before calibration, which helped to stabilize the sensor temperature and minimize its impact on calibration. The range of water temperatures for the calibration process was varied from about $0^{\circ} \mathrm{C}$ to $50^{\circ} \mathrm{C}$ to ensure that the range of naturally occurring temperatures in the field during a growing season was captured. The water temperature was changed by an interval of approximately $5^{\circ} \mathrm{C}$ for each calibration measurement. The water temperature was first decreased from $50^{\circ} \mathrm{C}$ to $0^{\circ} \mathrm{C}$, and then the calibration process was repeated by increasing the water temperature over the same range. Measurements were conducted in both directions to compensate for potential hysteretic performance of the various sensors (Doebelin and Manik, 1996). The time interval between each measurement was about $30 \mathrm{~min}$, and the entire experiment took about $10 \mathrm{~h}$ to complete.

A NIST-certified traceable temperature sensor was used as a reference, and special attention was paid to making sure that recordings from the sensors were taken only when the water temperature had reached equilibrium. The thermal camera was mounted to a support stand using a small threeprong dual-adjustable clamp. It was positioned $10 \mathrm{~cm}$ above the water target with well-mixed water surface (fig. 2). At this distance, the full frame of the camera captured an approximately $5.7 \mathrm{~cm} \times 4.6 \mathrm{~cm}$ rectangular area. This ensured that the full image scene focused only on the well-mixed water surface, and the temperature within this small area was assumed to be uniform.

Because each detector responds individually to a given temperature level, calibration equations were developed for each detector. Pixel values at different temperatures were calibrated by computing a least-squares linear regression

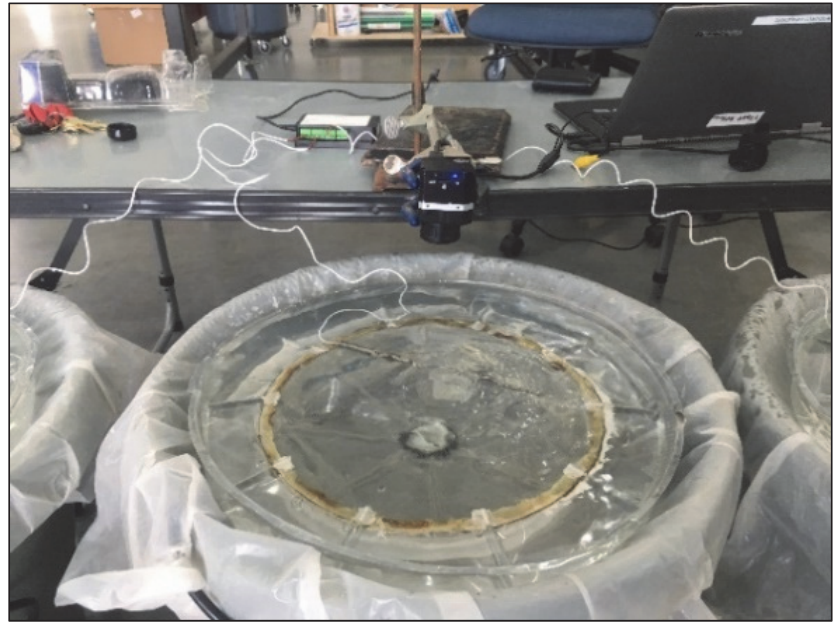

Figure 2. Thermal camera positioned $10 \mathrm{~cm}$ above the water surface for laboratory calibration.

relationship, and the intercepts and slopes were stored in variables that can be used for calibrating any raw image from this camera in the future. The linear relationships between raw digital numbers (DN) and radiance (RI) of the water target at different temperatures were established in the form:

$$
\mathrm{DN}=\text { Slope } \times \mathrm{RI}+\text { Intercept }
$$

The three RTDs and three handheld infrared thermometers (TG54 spot IR thermometer, FLIR Systems, Wilsonville, Ore.) were also calibrated during this process for use in collecting ground reference data during field operations. Measurements from the thermal camera and the infrared thermometers were synchronized with those of the traceable sensor, and the time of measurement was also recorded to identify data from the RTDs because they collected data continuously. The RTDs and NIST-certified temperature probe were placed near the center of the target without making physical contact with each other or breaking the water surface within the field of view of the camera. This allowed all temperature sensors to be calibrated simultaneously.

\section{NETD of Thermal Camera}

The NETD, which measures the thermal camera's signalto-noise ratio, or in other words its ability to distinguish between temperatures, was measured by looking at the temperature variability across the image when the field of view was locked on a constant, uniform temperature. This is a critical measure of the sensitivity of a thermal infrared camera, so we used the following method, based in part on the FLIR manual (FLIR, 2018a), to measure it.

Three water targets were set up using warm $\left(41.06^{\circ} \mathrm{C}\right)$, intermediate $\left(18.23^{\circ}\right)$ and cool $\left(0.18^{\circ} \mathrm{C}\right)$ water, and the position of the camera remained the same as mentioned above. The water temperatures were measured by the RTDs submerged in the bulk water. Sixty-four frames of the warm and cool targets were captured at $1 \mathrm{~s}$ intervals; these were used to calculate the average pixel-level response at both temperatures. Next, 128 sequential image frames were collected for the intermediate temperature target at $1 \mathrm{~s}$ intervals; these were used to calculate the standard deviation (temporal noise) of each pixel value. During the measurement periods, 
the standard deviations of the water temperature for the three targets (warm, intermediate, and cool) were $0.06^{\circ} \mathrm{C}, 0.02^{\circ} \mathrm{C}$, and $0.01^{\circ} \mathrm{C}$, respectively, indicating that the bulk water temperatures did not change significantly during the short measurement periods.

The cool response array was subtracted from the warm response array and then divided by the difference of their average bulk water temperatures. This gave us a responsivity array with units of counts per degree. Dividing the temporal noise array by the responsivity array produced an NETD array with units of Kelvin. Taking the average of all the pixels in this array (neglecting bad pixels) produced the NETD of the camera (FLIR, 2018a).

In this research, temperature measurements of the targets in thermal imagery are reported as (Doebelin and Manik, 1996):

$$
\text { Temperature }=T_{\text {avg }} \pm 3 \times s_{T_{\text {meas }}}
$$

where $T_{\operatorname{avg}}\left({ }^{\circ} \mathrm{C}\right)$ is the mean pixel measurements of a target in a thermal image, and $s_{\text {Tmeas }}$ is the standard deviation of these pixel measurements. In this way, the temperature measurement of the targets falls within three standard deviations of the mean $99.7 \%$ of the time.

\section{COMPENSATION FOR ATMOSPHERIC EFFECTS}

To compensate for atmospheric effects during flight operations, and to further optimize the outputs from the thermal camera, additional radiometric calibration was conducted. The aim of this process was to reduce the effects of thermal radiation emitted by the atmosphere between the camera and the objects on the ground by correcting the images to objects of known temperature on the ground.

\section{Research Site}

The field study was conducted in 2017 and 2020 at the Purdue Agronomy Center for Research and Education (ACRE) (West Lafayette, Ind.), which is located about $8 \mathrm{~km}$ (5 mi) northwest of Purdue University's main campus (fig. 3). All ground targets including the water targets were deployed on the grass lane or bare soil near the agricultural fields targeted during flight operations. Weather data were collected from the ACRE weather station (centered on $40^{\circ}$ $28^{\prime} 30.6^{\prime \prime} \mathrm{N}, 86^{\circ} 59^{\prime} 31.6^{\prime \prime} \mathrm{W}$ ). Flights for this analysis were conducted on three days in 2017 and 2020, and the weather information for each date is summarized in table 1 .

\section{Data Acquisition}

When the camera was used as part of flight operations, it was mounted on the underside of a rotary-wing DJI S1000 in 2017 and DJI M200 in 2020 (DJI, Shenzhen, China) and focused directly at the ground. The camera was fixed, not on a gimbal. The UAS altitude was set to $70 \mathrm{~m}$ above the field surface to achieve a ground resolution of about $7.17 \mathrm{~cm}$ pixel $^{-1}$. The camera was turned on about $20 \mathrm{~min}$ before each flight and triggered to take pictures every second during the flight. The camera was allowed to acclimate to the local air temperature and kept out of direct sunlight during the $20 \mathrm{~min}$ warmup period to minimize camera temperature drift during data collection. All targets (calibration and validation targets) were placed where they would be in the field of view of the camera during flight operations. In 2017, the calibration targets (including vegetative surface, spectral targets, and ground control points) and the water targets were visible in the same image. In 2020, the calibration targets (including bare soil, grass, water targets, ground control points, and spectral targets) were deployed away from each other, and

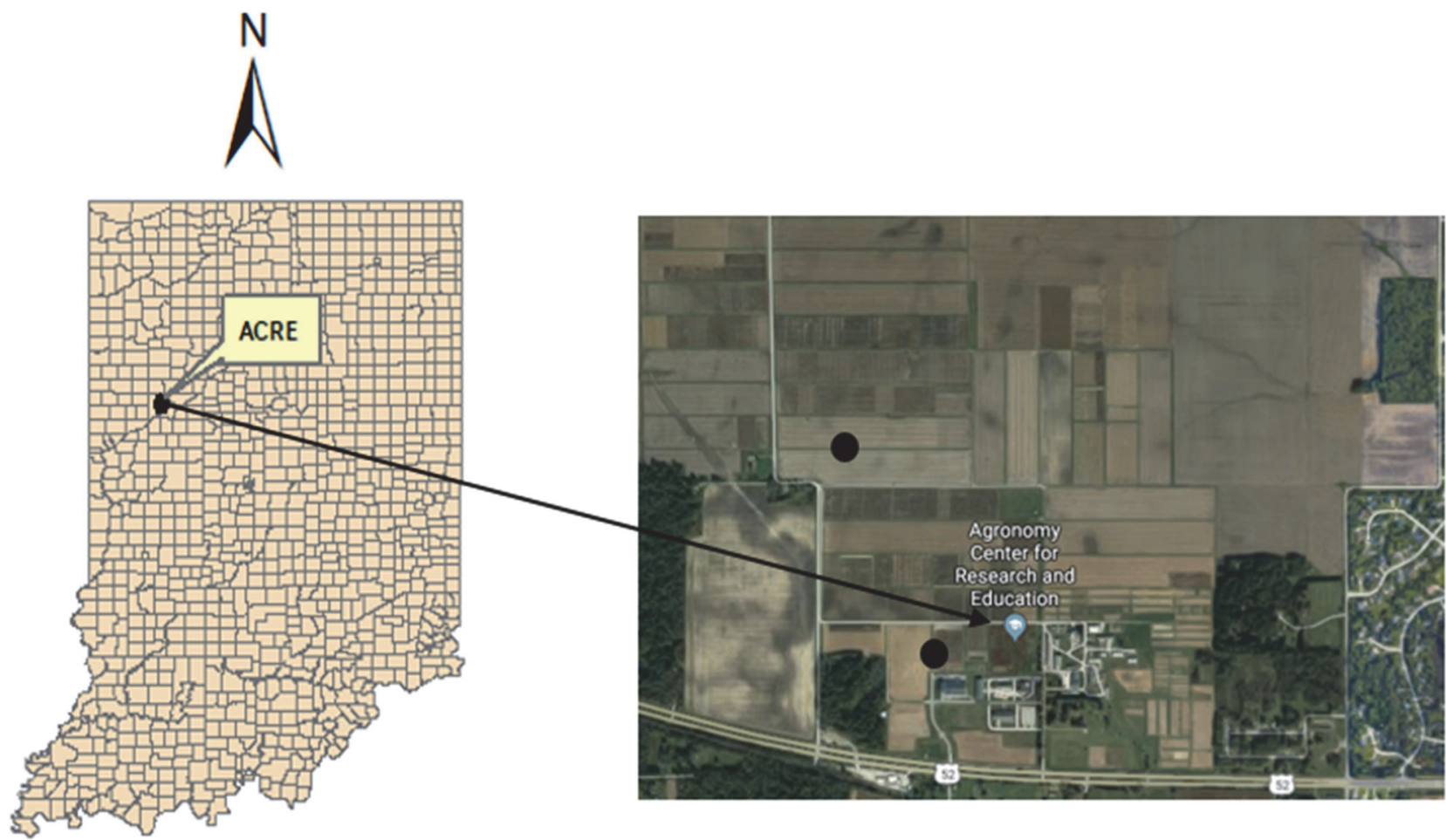

Figure 3. Location of the Purdue Agronomy Center for Research and Education (ACRE) and the 2017 and 2020 field sites. In the right image, the upper and lower dots indicate the 2017 and 2020 sites, respectively (image acquired from Google Maps). 
Table 1. Weather parameters for experimental days.

\begin{tabular}{cccc}
\hline & $\begin{array}{c}\text { Air } \\
\text { Temperature } \\
\left({ }^{\circ} \mathrm{C}\right)\end{array}$ & $\begin{array}{c}\text { Wind } \\
\text { Speed } \\
\left(\mathrm{m} \mathrm{s}^{-1}\right)\end{array}$ & $\begin{array}{c}\text { Relative } \\
\text { Humidity } \\
(\%)\end{array}$ \\
\hline 25 Aug. 2017 (16:30) & 22.6 & 2.3 & 44.5 \\
28 Sept. 2017 (17:00) & 22.1 & 2.7 & 43.2 \\
6 Aug. 2020 (17:30) & 24.2 & 1.2 & 51.0 \\
\hline
\end{tabular}

only one validation target could be seen in any individual image. These individual images were taken within $15 \mathrm{~min}$ of the images of ground calibration targets.

Water targets were visible multiple times during every flight. For instance, all three water targets appeared in three images on 25 August 2017 and in five images on 28 September 2017. In 2017, only one set of three water temperatures was used, while in 2020 , the temperatures of the three water targets were changed twice during flight operations, resulting in nine different temperatures. All water target temperatures were continuously monitored with submerged RTDs.

Only the images with the targets closest to the image center were used for atmospheric correction to reduce the effect of vignetting on temperature accuracy. We refer to these images as "seed images" in this article.

Ground reference data were collected using the handheld infrared thermometers calibrated as part of the laboratorybased calibration process. The handheld infrared thermometers, with an accuracy of $\pm 0.2^{\circ} \mathrm{C}$ after calibration, were used to measure at least four points within each ground feature to obtain an average radiative temperature. When taking a measurement, the thermometer was pointed directly down to avoid interference from direct solar radiation. The height of the handheld thermometer above the target was used to confirm that the spot measurement size fell completely within the desired target. Each handheld thermometer was shaded as much as possible during data collection to minimize the effect of solar heating on the thermometer measurements. The time of each handheld thermometer measurement was recorded, and measurements were taken before and after flight operations to check for significant changes in ground reference target temperatures. Ground reference values are represented by means \pm 3 times the standard deviations based on the laboratory calibration; however, when used to calculate bias, only the mean of the reference measurements is used.

Selected ground reference features must be visible in the thermal imagery, must be generally uniform in composition, and must not change temperature significantly during each day's flight operations. Temperature information for each ground reference target was extracted from the calibrated thermal imagery and was compared against the information from the handheld infrared thermometers. This provided an independent evaluation of the calibrated image temperatures.

\section{Calibration and Validation}

The raw images were first calibrated by applying the slope and intercept values, which were derived from the pixel-based calibration. The atmospheric correction relationships developed from the seed image using the detected and emitted radiance of the water targets were then applied to produce images in which the pixels represented the calibrated emitted radiance from the ground surface with minimal atmospheric effects. After this, radiance was converted to temperature for all images based on the emissivity of the surface material, and temperatures from additional ground reference targets were extracted from the images for evaluation purposes.

Evaluation of the calibration methods was conducted by comparing the calibrated image temperatures with the handheld infrared thermometer measurements of ground reference features including ground control points, vegetative surface, bare soil, water target and spectral calibration targets. All targets occupied four to nine pixels in the images; to be consistent, the four most central pixels were used to derive the temperatures from all imagery.

Bulk temperatures measured from the water targets at other times during the flight, not seed images, were used to evaluate the thermal drift of the camera during flight operations. The correction equation for each flight was then applied to all images taken during that flight. The entire calibration and validation process is summarized in figure 4 .

\section{RESULTS \\ LABORATORY BASED CALIBRATION RESULTS Thermal Camera Calibration}

Figure 5 shows the slope and intercept values from the linear calibration equations developed for each pixel of the thermal camera. Slope values were highest at the right and left edges of the camera's field of view (fig. 5a), while intercept values were highest in the middle (fig. 5b). This phenomenon is due to the vignetting effect of the camera lens on the resulting thermal images. The variation between thermal camera pixels was small, but the calibrated accuracy was best in the middle of the temperature range (fig. 6 and table 2). The error bounds from the calibration process indicate that most camera measurements fell within the $99.7 \%$ uncertainty range $\left( \pm 2.3^{\circ} \mathrm{C}\right)$, with exceptions arising at the highest and lowest temperatures used for calibration.

Figure 7 and table 2 illustrate how well the algorithm calibrated the raw images. The calibration process reduced the

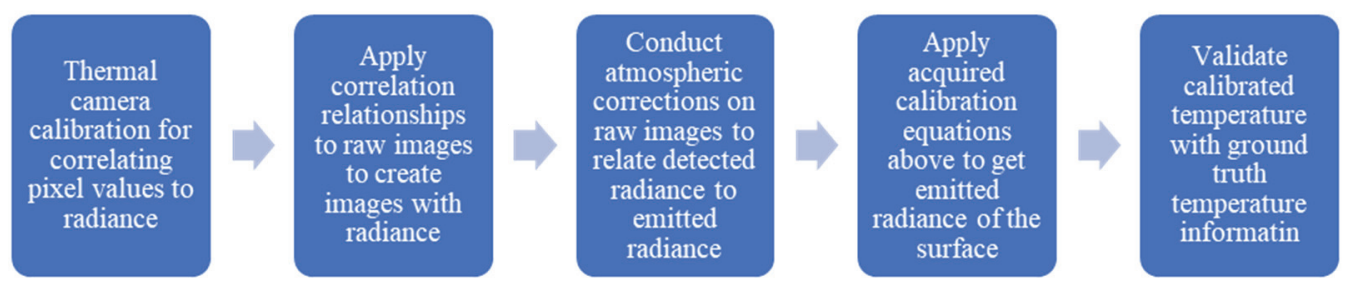

Figure 4. Flowchart of thermal imagery calibration and validation. 


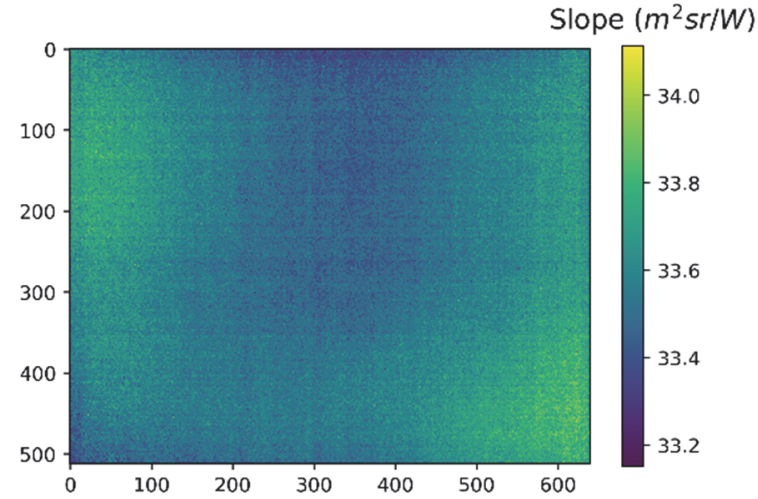

(a)

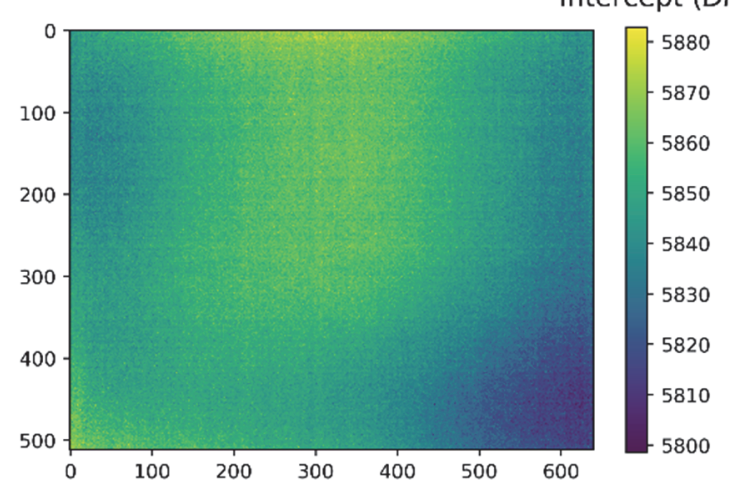

(b)

Figure 5. (a) Slope and (b) intercept values from the linear calibration equations developed for each thermal camera pixel. Images represent the entire field of view of the camera.

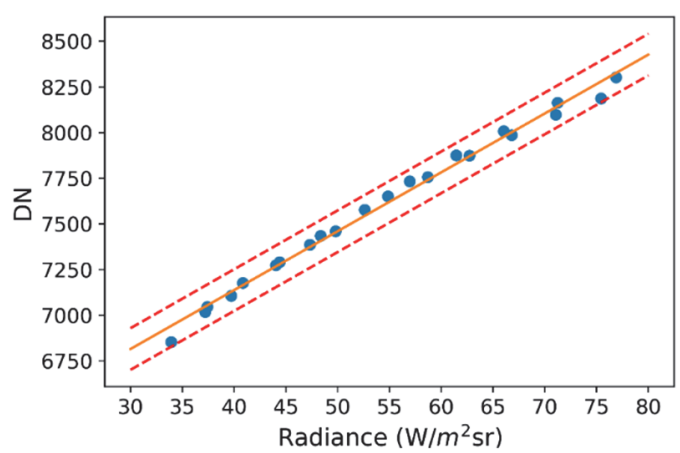

Figure 6. Calibration relationship between the camera digital number (DN) and the radiance of the water target across the range of bulk water temperatures used for calibration. The solid line indicates the average calibration equation for all pixels, while the dashed lines indicate $\mathbf{9 9 . 7 \%}$ error bounds. Data points are the mean DN value of the camera image at each temperature.

bias and also reduced the variance of the measured temperatures (fig. 7), especially in the range of temperatures that are dominant for agricultural applications. For the examples shown, the temperature bias decreased by as much as $5.32^{\circ} \mathrm{C}$ for the water target with a bulk temperature of $35.80^{\circ} \mathrm{C}$, while the standard deviation decreased by $0.28^{\circ} \mathrm{C}$ for the water target with a bulk temperature of $28.47^{\circ} \mathrm{C}$.

Table 2 also shows that, without calibration, the measurements from the thermal camera tend to overestimate the reference temperatures, while the measurements underestimate the reference temperatures after calibration. In addition, the
Table 2. Reference temperatures and mean temperatures extracted from imagery. Means include uncertainties, defined as \pm 3 standard deviations of all measurements collected for the same target. Means and uncertainties are presented for uncalibrated and calibrated images of the water target taken during the calibration process (temperatures are listed in chronological order).

\begin{tabular}{ccccc}
\hline $\begin{array}{c}\text { Reference } \\
\text { Temp. }\end{array}$ & $\begin{array}{c}\text { Uncalibrated } \\
\text { Temp. }\end{array}$ & $\begin{array}{c}\text { Calibrated } \\
\text { Temp. } \\
\left(T_{\text {ref },}{ }^{\circ} \mathrm{C}\right)\end{array}$ & $\begin{array}{c}\text { Uncalibrated } \\
\left(T_{\text {uncal }},{ }^{\circ} \mathrm{C}\right)\end{array}$ & $\begin{array}{c}\text { Calibrated } \\
\left(T_{\text {cal }}{ }^{\circ} \mathrm{C}\right)\end{array}$ \\
\hline 51.25 & $59.43 \pm 1.05$ & $47.54 \pm 0.36$ & $8.18 \pm 1.05$ & $-3.71 \pm 0.36$ \\
$\left(T_{\text {uncal }}-T_{\text {ref }}\right)$ & $\left(T_{\text {cal }}-T_{\text {ref }}\right)$ \\
45.84 & $53.76 \pm 1.06$ & $43.61 \pm 0.36$ & $7.92 \pm 1.06$ & $-2.23 \pm 0.36$ \\
40.61 & $47.45 \pm 0.66$ & $38.97 \pm 0.42$ & $6.84 \pm 0.66$ & $-1.64 \pm 0.42$ \\
35.80 & $42.11 \pm 1.00$ & $34.81 \pm 0.30$ & $6.31 \pm 1.00$ & $-0.99 \pm 0.30$ \\
30.89 & $36.32 \pm 0.86$ & $30.06 \pm 0.27$ & $5.43 \pm 0.86$ & $-0.83 \pm 0.27$ \\
25.86 & $30.06 \pm 1.11$ & $24.64 \pm 0.31$ & $4.20 \pm 1.11$ & $-1.22 \pm 0.31$ \\
20.71 & $24.25 \pm 1.05$ & $19.34 \pm 0.27$ & $3.54 \pm 1.05$ & $-1.37 \pm 0.27$ \\
15.64 & $18.44 \pm 1.05$ & $13.80 \pm 0.30$ & $2.80 \pm 1.05$ & $-1.84 \pm 0.30$ \\
10.87 & $13.85 \pm 1.35$ & $9.24 \pm 0.69$ & $2.98 \pm 1.35$ & $-1.63 \pm 0.69$ \\
6.00 & $8.50 \pm 1.35$ & $3.73 \pm 0.61$ & $2.50 \pm 1.35$ & $-2.27 \pm 0.61$ \\
0.71 & $0.71 \pm 1.21$ & $-4.67 \pm 0.43$ & $0.00 \pm 1.21$ & $-5.38 \pm 0.43$ \\
5.69 & $7.39 \pm 1.14$ & $2.56 \pm 0.36$ & $1.70 \pm 1.14$ & $-3.13 \pm 0.36$ \\
9.31 & $10.96 \pm 1.01$ & $6.30 \pm 0.90$ & $1.65 \pm 1.01$ & $-3.01 \pm 0.90$ \\
15.19 & $17.76 \pm 1.17$ & $13.14 \pm 0.39$ & $2.57 \pm 1.17$ & $-2.05 \pm 0.39$ \\
19.40 & $22.28 \pm 0.95$ & $17.49 \pm 0.77$ & $2.88 \pm 0.95$ & $-1.91 \pm 0.77$ \\
22.52 & $25.26 \pm 1.11$ & $20.28 \pm 0.28$ & $2.74 \pm 1.11$ & $-2.24 \pm 0.28$ \\
28.47 & $33.05 \pm 1.00$ & $27.26 \pm 0.34$ & $4.58 \pm 1.00$ & $-1.21 \pm 0.34$ \\
32.82 & $37.26 \pm 0.72$ & $30.84 \pm 0.35$ & $4.44 \pm 0.72$ & $-1.98 \pm 0.35$ \\
37.16 & $42.06 \pm 0.84$ & $34.77 \pm 0.18$ & $4.90 \pm 0.84$ & $-2.39 \pm 0.18$ \\
41.40 & $46.57 \pm 0.75$ & $38.30 \pm 0.20$ & $5.17 \pm 0.75$ & $-3.10 \pm 0.20$ \\
45.66 & $51.15 \pm 0.85$ & $41.73 \pm 0.21$ & $5.49 \pm 0.85$ & $-3.93 \pm 0.21$ \\
49.89 & $54.70 \pm 0.86$ & $44.28 \pm 0.44$ & $4.81 \pm 0.86$ & $-5.61 \pm 0.44$ \\
\hline
\end{tabular}

calibration bias is worse than the uncalibrated bias at the highest and lowest temperatures used for calibration. This is especially true for the cold water temperatures, as the calibrated bias is larger than or similar to the uncalibrated bias for all measurements less than $10^{\circ} \mathrm{C}$. The most significant bias is for the reference temperature of $0.71{ }^{\circ} \mathrm{C}$, where the calibrated bias is $5.38^{\circ} \mathrm{C}$, while there is no bias for the uncalibrated temperature. The calibrated bias exceeds the uncalibrated bias at a reference temperature of $49.89^{\circ} \mathrm{C}$, but not for any of the other high-temperature calibration points. One of the reasons for increased inaccuracy at extreme temperatures is that when the water temperature is significantly higher $\left(49.89^{\circ} \mathrm{C}\right)$ or lower $\left(0.71{ }^{\circ} \mathrm{C}, 5.69^{\circ} \mathrm{C}\right.$, and $\left.9.31^{\circ} \mathrm{C}\right)$ than the ambient temperature, the reflected thermal emissions from the background contribute a larger portion of the radiation detected by the thermal camera than that at intermediate temperatures $\left(10^{\circ} \mathrm{C}\right.$ to $\left.45^{\circ} \mathrm{C}\right)$ (FLIR 2018b). The root mean square error (RMSE) was reduced from $4.73^{\circ} \mathrm{C}$ to $2.74^{\circ} \mathrm{C}$ for the full temperature range and from $4.12^{\circ} \mathrm{C}$ to $1.70^{\circ} \mathrm{C}$ for the more limited intermediate temperature range $\left(10^{\circ} \mathrm{C}\right.$ to $\left.45^{\circ} \mathrm{C}\right)$.

\section{NETD Quantification}

The NETD for the thermal camera used in this study was calculated to be $145.5 \mathrm{mK}$. This is higher than the $50 \mathrm{mK}$ expected from the FLIR documentation. Because the NETD uncertainty can be either positive or negative, the camera can only distinguish temperature differences greater than $0.291 \mathrm{~K}$. To be more specific, if the temperature difference between objects in a thermal image is less than $0.291 \mathrm{~K}$ or $0.291^{\circ} \mathrm{C}$, then we cannot with confidence conclude that their temperatures are different. 


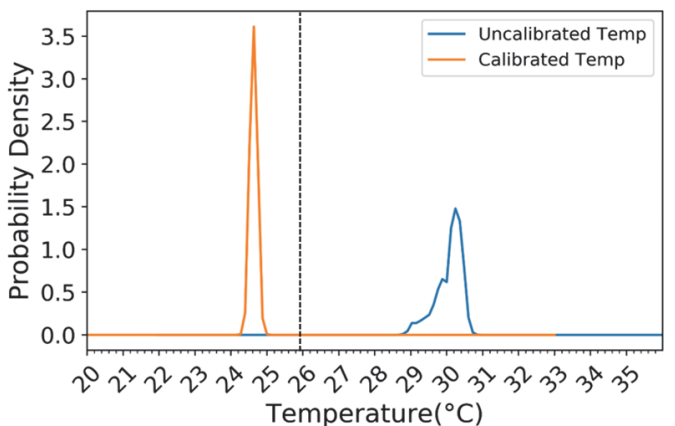

(a)

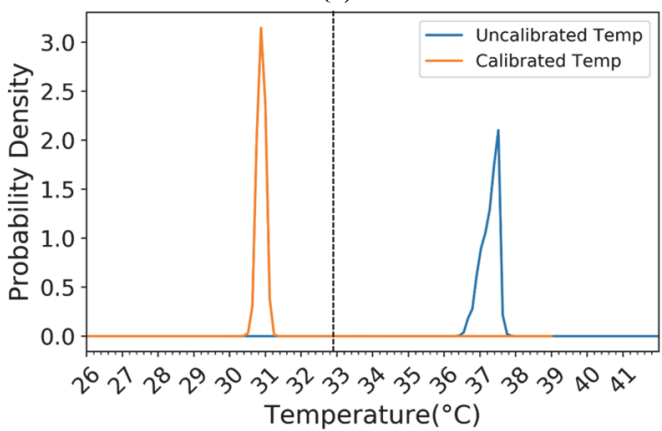

(c)

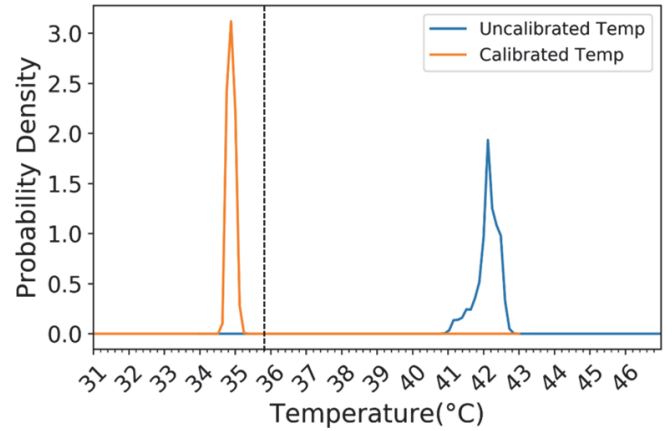

(b)

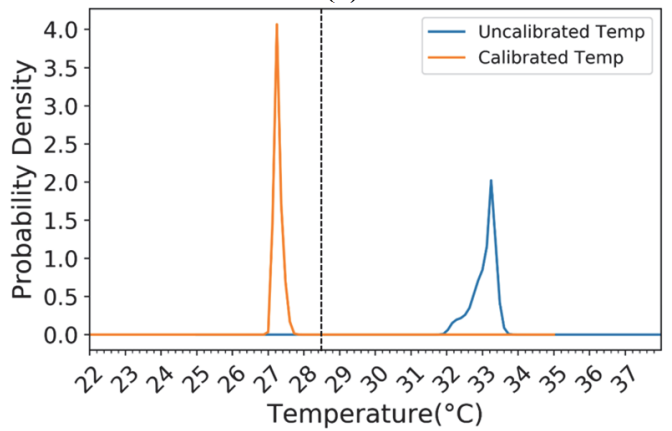

(d)

Figure 7. Temperature distributions for pixels of uncalibrated (blue) and calibrated (orange) thermal images over the water target blackbody with bulk temperatures of (a) $35.80^{\circ} \mathrm{C}$, (b) $25.86^{\circ} \mathrm{C}$, (c) $32.82^{\circ} \mathrm{C}$ and (d) $28.47^{\circ} \mathrm{C}$. Each bulk temperature is represented by a black dashed line.

\section{ATMOSPHERIC EFFECTS COMPENSATION}

The final process is to correct the thermal infrared images collected from the UAS platform for atmospheric effects. Flights on three dates (25 August 2017, 28 September 2017, and 6 August 2020) are used to demonstrate the method used to build atmospheric correction models using in-field water targets and validate those models versus supplemental ground reference data.

The emitted radiance and detected radiance of the water targets in 2017 are summarized in tables 3 and 4 and are used to derive linear atmospheric correction equations for the 25 August and 28 September flights. For both flights, the detected radiance of the water targets is lower than their emitted radiance, except for the cold target. This is because the temperature of the cold target was significantly lower than the measured air temperature, so it was more susceptible to atmospheric interference, which increased the emitted radiance collected at the sensor. For the warmer targets, the atmosphere attenuated their emitted radiance.

Table 3. Emitted radiance and sensor-detected radiance of water targets on 25 August 2017 (16:37:11).

\begin{tabular}{cccc}
\hline Water Target & $\begin{array}{c}\text { Temperature } \\
\left({ }^{\circ} \mathrm{C}\right)\end{array}$ & $\begin{array}{c}\text { Emitted } \\
\text { Radiance } \\
\left(\mathrm{W} \mathrm{m}^{-2} \mathrm{sr}^{-1}\right)\end{array}$ & $\begin{array}{c}\text { Detected } \\
\text { Radiance } \\
\left(\mathrm{W} \mathrm{m}^{-2} \mathrm{sr}^{-1}\right)\end{array}$ \\
\hline Cold & 8.56 & 37.62 & 39.74 \\
Intermediate & 24.73 & 49.58 & 47.39 \\
Hot & 33.89 & 57.29 & 49.94 \\
\hline
\end{tabular}

Table 4. Emitted radiance and sensor-detected radiance of water targets on 28 September 2017 (17:10:21).

\begin{tabular}{cccc}
\hline Water Target & $\begin{array}{c}\text { Temperature } \\
\left({ }^{\circ} \mathrm{C}\right)\end{array}$ & $\begin{array}{c}\text { Emitted } \\
\text { Radiance } \\
\left(\mathrm{W} \mathrm{m}^{-2} \mathrm{sr}^{-1}\right)\end{array}$ & $\begin{array}{c}\text { Detected } \\
\text { Radiance } \\
\left(\mathrm{W} \mathrm{m}^{-2} \mathrm{sr}^{-1}\right)\end{array}$ \\
\hline Cold & 1.05 & 32.76 & 39.54 \\
Intermediate & 22.70 & 47.96 & 46.61 \\
Hot & 34.93 & 58.20 & 56.60 \\
\hline
\end{tabular}

After applying both pixel-based calibration and atmospheric correction to the raw images (fig. 8a), radiance was converted to temperature based on the Planck function, and calibrated thermal images were generated (fig. 8b). Generally, calibration reduced the cooler vegetative surface temperature, while the warmer ground temperature was increased, thus the contrast of the images was enhanced (fig. 8c).

Table 5 shows that the bias between the ground reference temperatures and the temperatures extracted from the calibrated thermal imagery was reduced relative to the temperatures extracted from uncalibrated imagery. For the vegetative surface, the resulting change in detected temperature after calibration and correction for atmospheric effects $\left(0.29^{\circ} \mathrm{C}\right)$ is smaller than the NETD of the camera, and therefore not significant. However, the change in temperature registered for the white calibration panel is larger than the measurement uncertainty, with the bias between the raw temperatures and those from the calibrated and atmospherically corrected images decreased by $1.36^{\circ} \mathrm{C}$.

The effectiveness of the atmospheric correction was further tested by applying the calibration equation for $25 \mathrm{Au}-$ gust 2017 to subsequent images taken on the same day, in which at least one water target or ground reference target was visible (tables 6 and 7). Because all images were taken within $2 \mathrm{~min}$, the weather conditions were assumed to be stable during this period of time, and the same reference temperature measurement of each ground target was used for validation between images.

When applying the calibration equation to the water targets in subsequent images, the observed bias decreased to below $1.94^{\circ} \mathrm{C}$ for all cases. Meanwhile, the calibrated bias of the vegetative surface is less than $1.19^{\circ} \mathrm{C}$, which is the 

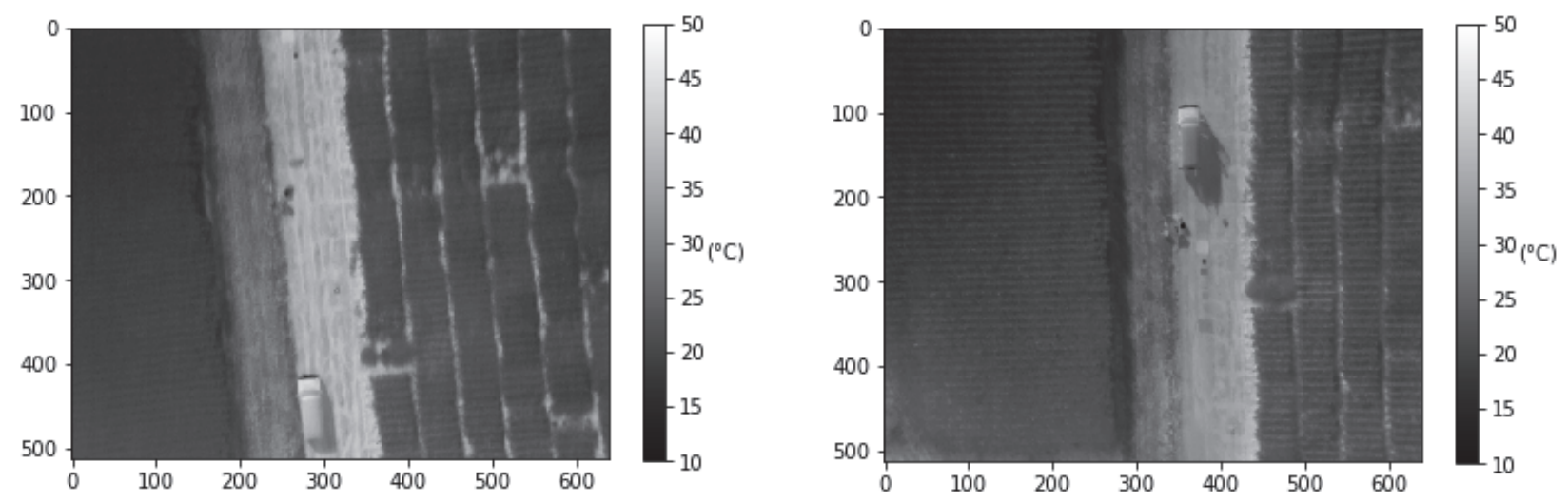

(a)
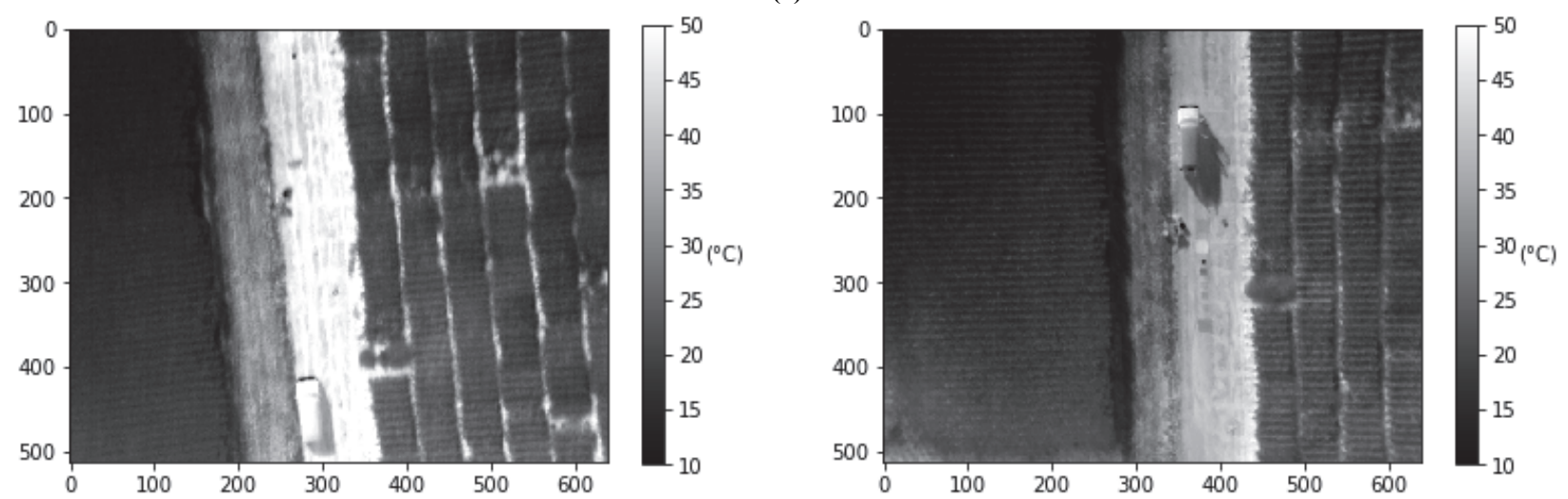

(b)
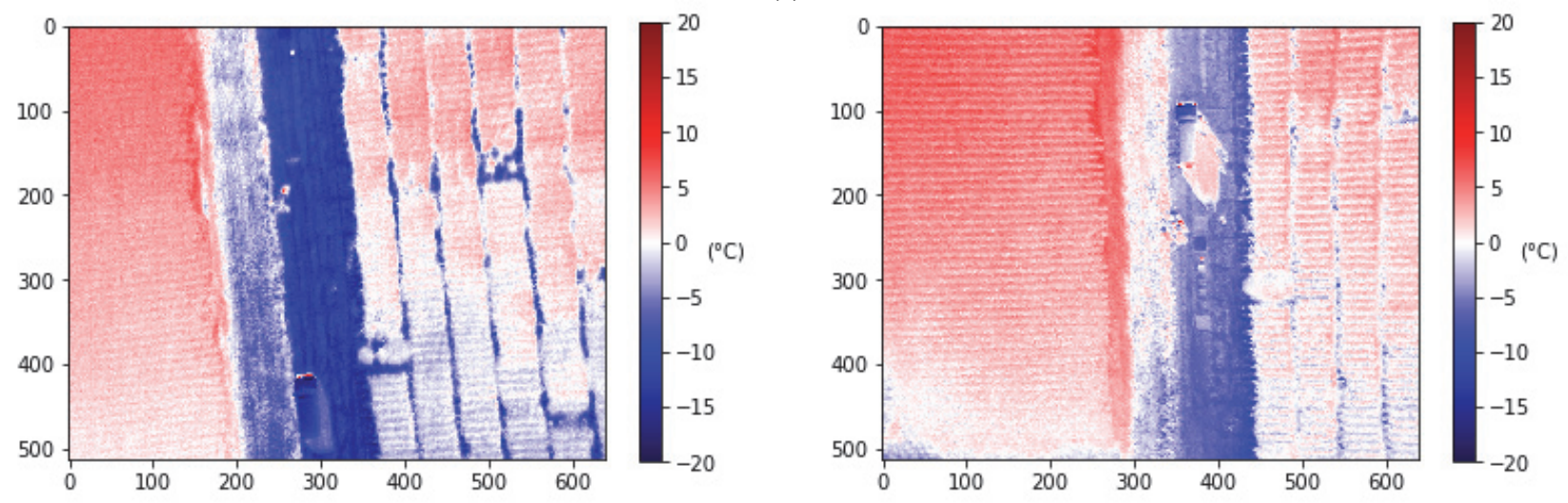

(c)

Figure 8. Thermal images from 25 August 2017 (left) and 28 September 2017 (right): (a) raw temperature images converted using FLIR radiometric calibration equations; (b) the same images after pixel-based calibration and atmospheric correction, and (c) the bias between thermal images (raw-corrected). The $X$ and $Y$ axes labels are image coordinates that help to identify the location of any pixel in the image.

Table 5. Comparison between reference, uncalibrated, and calibrated temperature measurements. Uncertainty, defined as \pm 3 standard deviations of all measurements collected for the same target, is presented after the mean values. The values in this table are for ground reference targets on 25 August 2017 (16:37:11). This image was used as the seed image for the atmospheric correction.

\begin{tabular}{|c|c|c|c|c|c|}
\hline $\begin{array}{c}\text { Ground Reference } \\
\text { Target }\end{array}$ & $\begin{array}{c}\text { Ground Reference } \\
\text { Temperature } \\
\left(T_{\text {ref }},{ }^{\circ} \mathrm{C}\right) \\
\end{array}$ & $\begin{array}{c}\text { Uncalibrated } \\
\text { Temperature } \\
\left(T_{\text {uncal }}{ }^{\circ} \mathrm{C}\right) \\
\end{array}$ & $\begin{array}{c}\text { Calibrated } \\
\text { Temperature } \\
\left(T_{\text {cal }},{ }^{\circ} \mathrm{C}\right) \\
\end{array}$ & $\begin{array}{c}\text { Uncalibrated } \\
\text { Bias }\left({ }^{\circ} \mathrm{C}\right) \\
\left(T_{\text {uncal }}-T_{\text {ref }}\right) \\
\end{array}$ & $\begin{array}{c}\text { Calibrated } \\
\text { Bias }\left({ }^{\circ} \mathrm{C}\right) \\
\left(T_{\text {cal }}-T_{\text {ref }}\right) \\
\end{array}$ \\
\hline Vegetative surface & $23.70 \pm 0.40$ & $22.31 \pm 0.93$ & $22.60 \pm 0.56$ & $-1.39 \pm 0.93$ & $-1.10 \pm 0.56$ \\
\hline White reference panel & $25.76 \pm 0.52$ & $23.39 \pm 0.62$ & $24.75 \pm 1.22$ & $-2.37 \pm 0.62$ & $-1.01 \pm 1.22$ \\
\hline
\end{tabular}

same or less than that of the initial validation (table 5). These results indicate that the atmospheric correction developed earlier can be applied to subsequent images to acquire accurate temperatures. The RMSE (Zhu et al., 2019) for all validation targets on 25 August 2017 was reduced from $4.56^{\circ} \mathrm{C}$ to $1.32^{\circ} \mathrm{C}$ after calibration.
Ground reference temperatures were collected for additional targets for the 28 September 2017 flight, resulting in a larger evaluation dataset (tables 8 and 9). For this flight, the uncalibrated bias ranged from $1.41^{\circ} \mathrm{C}$ to greater than $3.00^{\circ} \mathrm{C}$. After calibration and correction, the largest bias was $0.98^{\circ} \mathrm{C}$ for the black ground control point. However, measurement 
Table 6. Effectiveness of atmospheric correction when applied to non-seed images of the water targets taken on 25 August 2017 . The time of image acquisition is indicated. All temperature values are means \pm 3 standard deviations of all measurements collected for the same target. For the ground reference target, this includes several discrete measurements using handheld infrared thermometers; for the camera measurements, the standard deviation is based on pixel variation.

\begin{tabular}{|c|c|c|c|c|c|c|}
\hline $\begin{array}{l}\text { Ground } \\
\text { Reference } \\
\text { Target } \\
\end{array}$ & $\begin{array}{c}\text { Time of } \\
\text { Image } \\
\text { Acquisition }\end{array}$ & $\begin{array}{c}\text { Ground Reference } \\
\text { Temperature } \\
\left(T_{r e f},{ }^{\circ} \mathrm{C}\right)\end{array}$ & $\begin{array}{c}\text { Uncalibrated } \\
\text { Temperature } \\
\left(T_{\text {uncal }},{ }^{\circ} \mathrm{C}\right) \\
\end{array}$ & $\begin{array}{c}\text { Calibrated } \\
\text { Temperature } \\
\left(T_{c a l},{ }^{\circ} \mathrm{C}\right) \\
\end{array}$ & $\begin{array}{c}\text { Uncalibrated } \\
\text { Bias }\left({ }^{\circ} \mathrm{C}\right) \\
\left(T_{\text {uncal }}-T_{\text {ref }}\right) \\
\end{array}$ & $\begin{array}{c}\text { Calibrated } \\
\text { Bias }\left({ }^{\circ} \mathrm{C}\right) \\
\left(T_{c a l}-T_{r e f}\right)\end{array}$ \\
\hline \multirow{2}{*}{ Cold } & $16: 38: 53$ & 8.77 & $7.01 \pm 2.00$ & $7.14 \pm 1.28$ & $-1.76 \pm 2.00$ & $-1.63 \pm 0.83$ \\
\hline & $16: 38: 55$ & 8.77 & $10.98 \pm 4.22$ & $6.83 \pm 1.71$ & $2.21 \pm 4.22$ & $-1.94 \pm 1.71$ \\
\hline \multirow{2}{*}{ Intermediate } & $16: 38: 53$ & 24.75 & $19.61 \pm 1.06$ & $22.86 \pm 1.10$ & $-5.14 \pm 1.06$ & $-1.89 \pm 1.10$ \\
\hline & $16: 38: 55$ & 24.75 & $20.66 \pm 0.95$ & $23.35 \pm 1.79$ & $-4.09 \pm 0.95$ & $-1.40 \pm 1.79$ \\
\hline \multirow{2}{*}{ Hot } & $16: 38: 53$ & 33.72 & $24.94 \pm 0.36$ & $31.88 \pm 0.80$ & $-8.78 \pm 0.36$ & $-1.84 \pm 0.80$ \\
\hline & $16: 38: 55$ & 33.72 & $26.25 \pm 0.65$ & $33.26 \pm 1.60$ & $-7.47 \pm 0.65$ & $-0.46 \pm 1.60$ \\
\hline
\end{tabular}

Table 7. Effectiveness of atmospheric correction on non-seed images on 25 August 2017 based on vegetative surface temperature. All temperature values are means \pm 3 standard deviations of all measurements collected for the same target. For the ground reference target, this includes several discrete measurements using handheld infrared thermometers; for the camera measurements, standard deviation is based on pixel variation.

\begin{tabular}{|c|c|c|c|c|c|}
\hline $\begin{array}{c}\text { Time of } \\
\text { Reference Target } \\
\text { Image Acquisition }\end{array}$ & $\begin{array}{c}\text { Ground Reference } \\
\text { Temperature } \\
\left(T_{r e f},{ }^{\circ} \mathrm{C}\right) \\
\end{array}$ & $\begin{array}{c}\text { Uncalibrated } \\
\text { Temperature } \\
\left(T_{\text {uncal }},{ }^{\circ} \mathrm{C}\right) \\
\end{array}$ & $\begin{array}{c}\text { Calibrated } \\
\text { Temperature } \\
\left(T_{c a l},{ }^{\circ} \mathrm{C}\right) \\
\end{array}$ & $\begin{array}{c}\text { Uncalibrated } \\
\text { Bias }\left({ }^{\circ} \mathrm{C}\right) \\
\left(T_{\text {uncal }}-T_{\text {ref }}\right) \\
\end{array}$ & $\begin{array}{c}\text { Calibrated } \\
\text { Bias }\left({ }^{\circ} \mathrm{C}\right) \\
\left(T_{c a l}-T_{r e f}\right) \\
\end{array}$ \\
\hline $16: 37: 13$ & & $21.66 \pm 0.79$ & $23.86 \pm 1.28$ & $-2.04 \pm 0.93$ & $0.16 \pm 1.28$ \\
\hline $16: 38: 53$ & $23.70 \pm 0.40$ & $19.41 \pm 1.07$ & $23.46 \pm 0.30$ & $-4.29 \pm 1.07$ & $-0.24 \pm 0.30$ \\
\hline $16: 38: 55$ & & $19.83 \pm 0.75$ & $22.51 \pm 1.05$ & $-3.87 \pm 0.75$ & $-1.19 \pm 0.75$ \\
\hline
\end{tabular}

Table 8. Effectiveness of the atmospheric correction on non-seed images from 28 September 2017 . The ground reference temperature measurements are based on bulk temperature measurements from water targets. The temperature values are means \pm 3 standard deviations of all measurements collected for the same target.

\begin{tabular}{|c|c|c|c|c|c|c|}
\hline $\begin{array}{c}\text { Ground } \\
\text { Reference } \\
\text { Target }\end{array}$ & $\begin{array}{c}\text { Time of } \\
\text { Image } \\
\text { Acquisition }\end{array}$ & $\begin{array}{c}\text { Ground Reference } \\
\text { Temperature } \\
\left(T_{r e f},{ }^{\circ} \mathrm{C}\right)\end{array}$ & $\begin{array}{c}\text { Uncalibrated } \\
\text { Temperature } \\
\left(T_{\text {uncal }},{ }^{\circ} \mathrm{C}\right)\end{array}$ & $\begin{array}{c}\text { Calibrated } \\
\text { Temperature } \\
\left(T_{c a l},{ }^{\circ} \mathrm{C}\right)\end{array}$ & $\begin{array}{c}\text { Uncalibrated } \\
\text { Bias }\left({ }^{\circ} \mathrm{C}\right) \\
\left(T_{\text {uncal }}-T_{r e f}\right)\end{array}$ & $\begin{array}{c}\text { Calibrated } \\
\text { Bias }\left({ }^{\circ} \mathrm{C}\right) \\
\left(T_{c a l}-T_{r e f}\right)\end{array}$ \\
\hline \multirow{4}{*}{ Cold } & $17: 10: 19$ & 1.07 & $5.89 \pm 1.42$ & $2.39 \pm 0.49$ & $4.82 \pm 1.42$ & $1.32 \pm 0.49$ \\
\hline & $17: 10: 23$ & 1.05 & $8.29 \pm 2.01$ & $2.69 \pm 1.63$ & $7.24 \pm 2.01$ & $1.64 \pm 1.63$ \\
\hline & $17: 11: 59$ & 1.10 & $16.17 \pm 3.23$ & $2.59 \pm 0.52$ & $15.07 \pm 3.23$ & $1.49 \pm 0.52$ \\
\hline & $17: 12: 01$ & 1.10 & $15.04 \pm 2.24$ & $2.97 \pm 0.17$ & $13.94 \pm 2.24$ & $1.87 \pm 0.17$ \\
\hline \multirow{4}{*}{ Intermediate } & $17: 10: 19$ & 22.70 & $20.82 \pm 0.96$ & $21.07 \pm 1.77$ & $-1.88 \pm 0.96$ & $-1.63 \pm 1.36$ \\
\hline & $17: 10: 23$ & 22.72 & $23.47 \pm 0.86$ & $22.23 \pm 1.01$ & $0.75 \pm 0.86$ & $-0.49 \pm 1.01$ \\
\hline & $17: 11: 59$ & 22.76 & $29.26 \pm 0.92$ & $21.04 \pm 2.02$ & $6.5 \pm 0.92$ & $-1.72 \pm 2.02$ \\
\hline & $17: 12: 01$ & 22.76 & $27.93 \pm 1.12$ & $21.08 \pm 0.41$ & $5.17 \pm 1.12$ & $-1.68 \pm 0.41$ \\
\hline \multirow{4}{*}{ Hot } & $17: 10: 19$ & 34.93 & $30.91 \pm 0.87$ & $33.94 \pm 0.84$ & $-4.02 \pm 0.87$ & $-0.99 \pm 0.84$ \\
\hline & $17: 10: 23$ & 34.90 & $33.34 \pm 0.48$ & $36.01 \pm 0.65$ & $-1.56 \pm 0.48$ & $1.11 \pm 0.65$ \\
\hline & $17: 11: 59$ & 34.67 & $38.84 \pm 0.33$ & $36.10 \pm 1.58$ & $4.17 \pm 0.33$ & $1.43 \pm 1.58$ \\
\hline & $17: 12: 01$ & 34.67 & $37.22 \pm 0.61$ & $35.07 \pm 1.51$ & $2.55 \pm 0.61$ & $0.40 \pm 1.51$ \\
\hline
\end{tabular}

Table 9. Comparison between ground reference, uncalibrated, and calibrated temperature measurements for targets in the seed image (shown in bold) and non-seed images for 28 September 2017. The ground reference temperature measurements were made using handheld infrared thermometers for a selection of points within each ground-based target. The values are means \pm 3 standard deviations of all measurements collected for the same target.

\begin{tabular}{|c|c|c|c|c|c|c|}
\hline $\begin{array}{l}\text { Ground } \\
\text { Reference } \\
\text { Target }\end{array}$ & $\begin{array}{c}\text { Time of } \\
\text { Image } \\
\text { Acquisition }\end{array}$ & $\begin{array}{c}\text { Ground Reference } \\
\text { Temperature } \\
\left(T_{r e f},{ }^{\circ} \mathrm{C}\right)\end{array}$ & $\begin{array}{c}\text { Uncalibrated } \\
\text { Temperature } \\
\left(T_{\text {uncal }},{ }^{\circ} \mathrm{C}\right)\end{array}$ & $\begin{array}{c}\text { Calibrated } \\
\text { Temperature } \\
\left(T_{c a l},{ }^{\circ} \mathrm{C}\right)\end{array}$ & $\begin{array}{c}\text { Uncalibrated } \\
\text { Bias }\left({ }^{\circ} \mathrm{C}\right) \\
\left(T_{\text {uncal }}-T_{\text {ref }}\right)\end{array}$ & $\begin{array}{c}\text { Calibrated } \\
\text { Bias }\left({ }^{\circ} \mathrm{C}\right) \\
\left(T_{c a l}-T_{r e f}\right)\end{array}$ \\
\hline \multirow{3}{*}{$\begin{array}{l}\text { White ground } \\
\text { control point }\end{array}$} & $17: 10: 21$ & \multirow{3}{*}{$22.32 \pm 0.35$} & $25.27 \pm 1.40$ & $22.97 \pm 0.98$ & $2.95 \pm 1.40$ & $0.65 \pm 0.98$ \\
\hline & $17: 11: 59$ & & $31.09 \pm 0.49$ & $23.26 \pm 1.43$ & $8.77 \pm 0.49$ & $0.94 \pm 1.43$ \\
\hline & $17: 12: 01$ & & $30.29 \pm 2.35$ & $23.62 \pm 1.87$ & $7.97 \pm 2.35$ & $1.30 \pm 1.87$ \\
\hline \multirow{5}{*}{$\begin{array}{l}\text { Black ground } \\
\text { control point }\end{array}$} & $17: 10: 19$ & \multirow{5}{*}{$31.19 \pm 0.35$} & $28.11 \pm 1.53$ & $29.78 \pm 1.66$ & $-3.08 \pm 1.53$ & $-1.41 \pm 1.66$ \\
\hline & $17: 10: 21$ & & $28.10 \pm 1.74$ & $30.21 \pm 0.81$ & $-3.09 \pm 1.74$ & $-0.98 \pm 0.81$ \\
\hline & $17: 10: 23$ & & $29.87 \pm 0.99$ & $30.55 \pm 0.46$ & $-1.32 \pm 0.99$ & $-0.64 \pm 0.46$ \\
\hline & $17: 11: 59$ & & $35.32 \pm 3.10$ & $30.69 \pm 1.54$ & $4.13 \pm 3.10$ & $-0.50 \pm 1.54$ \\
\hline & $17: 12: 01$ & & $33.29 \pm 1.31$ & $30.02 \pm 1.94$ & $2.10 \pm 1.31$ & $-1.17 \pm 1.94$ \\
\hline \multirow{5}{*}{$\begin{array}{c}\text { Vegetative } \\
\text { surface }\end{array}$} & $17: 10: 19$ & \multirow{5}{*}{$23.14 \pm 0.36$} & $21.10 \pm 0.95$ & $21.81 \pm 1.54$ & $-2.04 \pm 0.95$ & $-1.33 \pm 1.54$ \\
\hline & 17:10:21 & & $24.55 \pm 0.43$ & $23.02 \pm 0.83$ & $1.41 \pm 0.43$ & $-0.12 \pm 0.83$ \\
\hline & $17: 10: 23$ & & $24.29 \pm 1.18$ & $23.38 \pm 1.23$ & $1.15 \pm 1.18$ & $0.24 \pm 1.23$ \\
\hline & $17: 11: 59$ & & $29.01 \pm 0.91$ & $22.32 \pm 0.40$ & $5.87 \pm 0.91$ & $-0.82 \pm 0.40$ \\
\hline & $17: 12: 01$ & & $28.04 \pm 0.68$ & $21.67 \pm 0.99$ & $4.90 \pm 0.68$ & $-1.47 \pm 0.99$ \\
\hline \multirow{4}{*}{$\begin{array}{l}\text { White } \\
\text { reference } \\
\text { panel }\end{array}$} & $17: 10: 19$ & \multirow{4}{*}{$25.01 \pm 1.64$} & $19.47 \pm 1.34$ & $23.71 \pm 1.01$ & $-5.54 \pm 1.34$ & $-1.30 \pm 1.01$ \\
\hline & 17:10:21 & & $21.33 \pm 1.64$ & $25.20 \pm 1.09$ & $-3.68 \pm 1.64$ & $0.19 \pm 1.09$ \\
\hline & $17: 11: 59$ & & $28.71 \pm 0.82$ & $26.03 \pm 1.45$ & $3.70 \pm 0.82$ & $1.02 \pm 1.45$ \\
\hline & $17: 12: 01$ & & $27.18 \pm 1.71$ & $25.41 \pm 1.84$ & $2.17 \pm 1.71$ & $0.40 \pm 1.84$ \\
\hline
\end{tabular}


uncertainty increased after calibration for the vegetative surface measurements.

The atmospheric calibration was again evaluated by applying it to other images from the same day in which at least two of the ground targets or water targets were visible. When applying the atmospheric calibration equation to the water targets that appeared in images not used to seed the atmospheric correction equation, the bias decreased, with an average absolute calibrated bias of $1.87^{\circ} \mathrm{C}$. Even with only $2 \mathrm{~s}$ between images, there was variation in the temperatures extracted from the thermal infrared images. There are multiple potential causes for these variations. As noted previously, the performance of each pixel (detector) is different, so even though we assumed that the reference temperatures of the ground targets did not change in such a short period of time, the measurements can change because they are in a different part of the camera's sensor array. Finally, the performance of the camera can fluctuate with time due to the lack of a cooling mechanism, which can lead to thermal drift in the instrument.

Temperature bias increased for the white ground control point, vegetative surface, and white reference panel between the seed image and the other images (table 9). After calibration and atmospheric correction, the difference between the calibrated bias of earlier images (17:10:19 and 17:10:23) and later images (17:11:59 and 17:12:01) was not consistent; however, the RMSE of all validation targets on this day decreased from $6.36^{\circ} \mathrm{C}$ to $1.24^{\circ} \mathrm{C}$.

The results indicate that the calibration and atmospheric correction method can be applied to the image from which it was developed (seed image) as well as to other images collected during the same flight. While there was increased variability and no consistent bias in the temperatures extracted from the non-seed images, the calibration and atmospheric correction method reduced the RMSE in all cases. While these experiments were not specifically designed to quantify thermal drift over the duration of the flight, the results illustrate that drift can be managed over a relatively short flight using these correction methods.

\section{ACCURACY ASSESSMENT OF USING THREe WATER TARgets}

To further evaluate the effectiveness of atmospheric correction with in-field water targets and to assess the impact of the number of target temperatures on the accuracy of the correction method, an additional experiment was conducted in 2020. During the flight on 6 August 2020, the three water target temperatures were adjusted twice by adding additional cold water. This resulted in flights with a total of nine different target temperatures. Atmospheric correction equations were developed using two to nine temperatures, and all possible combinations were evaluated.

Using any three water target temperatures yielded a large range in RMSE, from nearly $0.69^{\circ} \mathrm{C}$ to $7.93^{\circ} \mathrm{C}$, while using all nine temperatures resulted in an RMSE of $0.86^{\circ} \mathrm{C}$. However, when the temperatures of the three water targets are carefully set, such that the difference between each target is at least $4^{\circ} \mathrm{C}$ and the range between the hottest and coldest targets is greater than $25^{\circ} \mathrm{C}$, the variability in RMSE can be constrained. The first criterion ensures that the water target

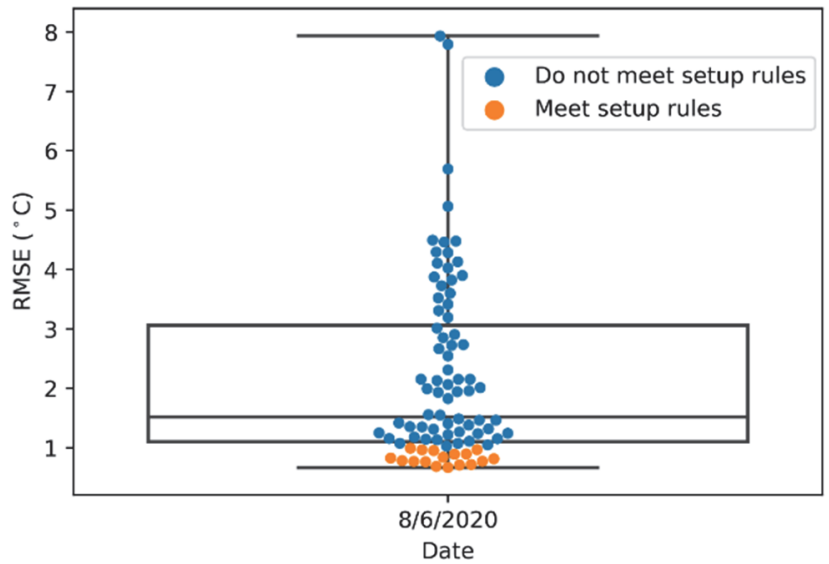

Figure 9. Distribution of RMSE between ground reference temperatures and thermal image estimated temperatures when using all combinations of three water targets selected from all nine temperature targets. The RMSE for each model is shown as a dot. The distribution of RMSE for all combinations is shown with a box plot, where the top whisker indicates the worst RMSE, the top of the box indicates the 25th percentile RMSE, the middle line indicates the median RMSE, the bottom of the box indicates the 75th percentile RMSE, and the lower whisker indicates the lowest RMSE. Orange dots indicate RMSE values for sets of three targets that meet the setup criteria, and blue dots indicate RMSE values for those that do not meet the setup criteria.

temperatures can be differentiated in the thermal images, meaning that the temperatures must be farther apart than the in-field temperature uncertainty. Because this uncertainty can be slightly higher than $\pm 1^{\circ} \mathrm{C}$, the $4^{\circ} \mathrm{C}$ buffer ensures that they are distinguishable. The second criterion ensures that target temperatures are selected for current conditions.

Analysis of the dataset shows that if the minimum temperature is less than $10^{\circ} \mathrm{C}$, the maximum temperature is above $35^{\circ} \mathrm{C}$, and no water targets are closer than $4{ }^{\circ} \mathrm{C}$ from each other, then the RMSE is always less than $1.00^{\circ} \mathrm{C}$ (fig. 9). If the temperature range criterion is eased to $20^{\circ} \mathrm{C}$, then there is only a $64 \%$ chance that the RMSE will be less than $1.49^{\circ} \mathrm{C}$. The water target temperatures used for all analyses in the previous sections conformed to these characteristics.

\section{DiscuSSION}

Inexpensive, uncooled thermal infrared cameras mounted on UAS are becoming an increasingly important method of measuring various land surface temperatures, with the expectation that derived variables, such as latent heat flux, will eventually be computed from the resulting images. However, without appropriate calibration and correction of atmospheric effects, the temperature bias can be significant. This study presents a novel pixel-based calibration method and in-field atmospheric correction method and quantifies the resulting reduction in bias and uncertainty in temperature estimates from a small, uncooled thermal infrared camera. The use of such cameras for UAS is still relatively new, so there are currently only a few similar studies, but there is a larger body of work using cooled cameras on satellite and aircraft platforms (Jensen et al., 2014).

For calibration accuracy, Budzier and Gerlach (2015) and Ribeiro-Gomes et al. (2017) reported after-calibration uncertainties of $\pm 1.00^{\circ} \mathrm{C}$ and approximately $\pm 1.50^{\circ} \mathrm{C}$ for uncooled 
thermal cameras, respectively (without reporting standard deviations). This is similar to the uncertainty of $\pm 1.70^{\circ} \mathrm{C}$ reported here. For atmospheric correction, uncertainty ranges from $\pm 0.89^{\circ} \mathrm{C}$ to $\pm 2.00^{\circ} \mathrm{C}$ have been reported in the literature using MODTRAN and local measurements to derive the terms in the governing equation (eq. 1) for radiation propagation for UAS-based sensors (Berni et al., 2009b; TorresRua, 2017) and from $\pm 1.00^{\circ} \mathrm{C}$ to $\pm 2.00^{\circ} \mathrm{C}$ for satellite-based sensors (Schott et al., 2012; O’Donnell et al., 2002), which supports the conclusion that the accuracy reported here (less than $\pm 1.32^{\circ} \mathrm{C}$ ) is acceptable, given the quality of the camera used.

It should be noted that previous studies used a variety of camera models, which had an impact on their calibration results. The camera used in the present research has a manufacturer's uncertainty of $\pm 5.00^{\circ} \mathrm{C}$, while the uncertainty of many of the cameras used in previous studies (specifically Ribeiro-Gomes et al., 2017; Berni et al., 2009b; Torres-Rua, 2017) was $\pm 2.00^{\circ} \mathrm{C}$. Given that the cameras used in previous studies had higher base accuracy, the ability of the method described here to provide a similar range of uncertainty with a lower-accuracy camera is significant.

The accuracy reported in this research is sufficient to differentiate the canopy from bare soil, with an average temperature difference of $7.40^{\circ} \mathrm{C}$ for the flights reported here. How the reported accuracy will affect latent heat estimates is still being determined. Challenges remain for the use of thermal infrared cameras when temperature accuracy is important. The water targets used in this research are cumbersome and time-consuming to set up, which limits the number targets that can be deployed in the field as well as the locations at which they can be deployed. In addition, the performance of the water targets has only been tested under a limited number of atmospheric and surface conditions. How well they will work under more extreme weather conditions and for targets with different emissivity is a subject for future research.

\section{CONCLUSION}

A method was presented to improve the accuracy of temperature observations from a UAS-based uncooled thermal infrared camera using a combination of laboratory calibration and in-field water targets for atmospheric correction. The pixel-based thermal calibration method presented here was able to reduce the measurement uncertainty across all the pixels in the images, thus improving the accuracy and reducing the between-pixel variability of the measurements. After calibration, the camera was more accurate over the range of normal temperatures within its field of view during the growing season. The results suggest that a non-linear calibration function might be more appropriate if a wider calibration range is required.

During field calibration, the RMSE values relative to ground reference targets for two flights in 2017 were reduced from $6.36^{\circ} \mathrm{C}$ to $1.24^{\circ} \mathrm{C}$ and from $4.56^{\circ} \mathrm{C}$ to $1.32^{\circ} \mathrm{C}$, respectively. The results also indicate that building a single atmospheric correction relationship using the seed image and the ground-based water targets was sufficient to reduce measurement uncertainty in all cases for the duration of the flight.

Further data analysis from flights in 2020 indicated that when using water targets with three temperatures, a minimum temperature less than $10^{\circ} \mathrm{C}$, and a maximum temperature above $35^{\circ} \mathrm{C}$, the RMSE of the calibrated temperature will always be less than $1.00^{\circ} \mathrm{C}$. If the temperature range requirement is eased to $20^{\circ} \mathrm{C}$, then there is only a $64 \%$ chance that the RMSE will be less than $1.49^{\circ} \mathrm{C}$.

Calibration and atmospheric correction increased the range of measured temperatures in the images and increased the image contrast, which may help with identification of tiepoints and stitching of images together to form whole-field mosaics. Image calibration and atmospheric correction are important for achieving the best accuracy in measured temperatures, which will become even more important as vegetative surface temperature is used to estimate latent heat flux and is included in multi-sensor fusion to better predict crop biomass and yield.

Future work includes improving the design of the water targets to incorporate lessons learned after multiple seasons of use, with a focus on making the targets more mobile with a larger water surface area to increase their visibility in the thermal imagery collected from UAS platforms, and testing the performance of the developed calibration methods under a broader range of weather and surface conditions.

\section{ACKNOWLEDGEMENTS}

We thank Anthony Hearst for building prototypes of the water targets, John Evan Flatt and Peter Rusche for piloting the UAS and in helping deploy the water targets in the field, and Elaina Ludwig for collecting ground reference data. The work presented here was funded in part by the Advanced Research Projects Agency-Energy (ARPA-E) of the U.S. Department of Energy under Award No. DE-AR0001135. The views and opinions of the authors expressed herein do not necessarily state or reflect those of the U.S. Government or any agency thereof. Mention of trade names or commercial products is not an endorsement or recommendation for use by the U.S. Government.

\section{REFERENCES}

Barbagallo, S., Consoli, S., \& Russo, A. (2009). A one-layer satellite surface energy balance for estimating evapotranspiration rates and crop water stress indexes. Sensors, 9(1), 1-21. https://doi.org/10.3390/s90100001

Barsi, J. A., Barker, J. L., \& Schott, J. R. (2003). An atmospheric correction parameter calculator for a single thermal band earthsensing instrument. Proc. IEEE Intl. Geoscience and Remote Sensing Symp. (Vol. 5, pp. 3014-3016). Piscataway, NJ: IEEE. https://doi.org/10.1109/IGARSS.2003.1294665

Berni, J. A., Zarco-Tejada, P. J., Sepulcre-Canto, G., Fereres, E., \& Villalobos, F. (2009a). Mapping canopy conductance and CWSI in olive orchards using high-resolution thermal remote sensing imagery. Remote Sens. Environ., 113(11), 2380-2388. https://doi.org/10.1016/j.rse.2009.06.018

Berni, J. A., Zarco-Tejada, P. J., Suarez, L., \& Fereres, E. (2009b). Thermal and narrowband multispectral remote sensing for vegetation monitoring from an unmanned aerial vehicle. IEEE 
Trans. Geosci. Remote Sens., 47(3), 722-738. https://doi.org/10.1109/TGRS.2008.2010457

Budzier, H., \& Gerlach, G. (2015). Calibration of uncooled thermal infrared cameras. J. Sens. Sens. Syst., 4, 187-197. https://doi.org/10.5194/jsss-4-187-2015

Campbell, G. S., \& Norman, J. M. (2012). An introduction to environmental biophysics (2nd Ed.). New York, NY: Springer Science \& Business Media.

Cherkauer, K. A., Burges, S. J., Handcock, R. N., Kay, J. E., Kampf, S. K., \& Gillespie, A. R. (2005). Assessing satellitebased and aircraft-based thermal infrared remote sensing for monitoring Pacific Northwest river temperature. JAWRA, 41(5), 1149-1159. https://doi.org/10.1111/j.1752-1688.2005.tb03790.x

Doebelin, E. O., \& Manik, D. N. (1996). Measurement systems: Application and design. New York, NY: McGraw-Hill.

Eitel, J. U., Keefe, R. F., Long, D. S., Davis, A. S., \& Vierling, L. A. (2010). Active ground optical remote sensing for improved monitoring of seedling stress in nurseries. Sensors, 10(4), 28432850. https://doi.org/10.3390/s100402843

FLIR. (2018a). How is NETD of cooled measured? Wilsonville, OR: FLIR Systems. Retrieved from http://flir.custhelp.com/app/answers/detail/a_id/128/ /how-isnedt-measured

FLIR. (2018b). Infrared camera accuracy and uncertainty in plain language. Wilsonville, OR: FLIR Systems. Retrieved from https://www.flir.com/discover/rd-science/infrared-cameraaccuracy-and-uncertainty-in-plain-language/

Gowda, P. H., Chavez, J. L., Colaizzi, P. D., Evett, S. R., Howell, T. A., \& Tolk, J. A. (2008). ET mapping for agricultural water management: Present status and challenges. Irrig. Sci., 26(3), 223-237. https://doi.org/10.1007/s00271-007-0088-6

Handcock, R. N., Gillespie, A. R., Cherkauer, K. A., Kay, J. E., Burges, S. J., \& Kampf, S. K. (2006). Accuracy and uncertainty of thermal-infrared remote sensing of stream temperatures at multiple spatial scales. Remote Sens. Environ., 100(4), 427-440. https://doi.org/10.1016/j.rse.2005.07.007

Hoffmann, H., Nieto, H., Jensen, R., Guzinski, R., Zarco-Tejada, P., \& Friborg, T. (2016). Estimating evaporation with thermal UAV data and two-source energy balance models. Hydrol. Earth Syst. Sci., 20(2), 697-713. https://doi.org/10.5194/hess-20-697-2016

Ishimwe, R., Abutaleb, K., \& Ahmed, F. (2014). Applications of thermal imaging in agriculture: A review. Adv. Remote Sens., 3(3), 128-140. https://doi.org/10.4236/ars.2014.33011

Jensen, A. M., McKee, M., \& Chen, Y. (2014). Procedures for processing thermal images using low-cost microbolometer cameras for small unmanned aerial systems. Proc. IEEE Geoscience and Remote Sensing Symp. (pp. 2629-2632). Piscataway, NJ: IEEE. https://doi.org/10.1109/IGARSS.2014.6947013

Kay, J. E., Kampf, S. K., Handcock, R. N., Cherkauer, K. A., Gillespie, A. R., \& Burges, S. J. (2005). Accuracy of lake and stream temperatures estimated from thermal infrared images. JAWRA, 41(5), 1161-1175. https://doi.org/10.1111/j.17521688.2005.tb03791.x

Khanal, S., Fulton, J., \& Shearer, S. (2017). An overview of current and potential applications of thermal remote sensing in precision agriculture. Comput. Electron. Agric., 139, 22-32. https://doi.org/10.1016/j.compag.2017.05.001

Kozak, J. A., Aiken, R. M., Flerchinger, G. N., Nielsen, D. C., Ma, L., \& Ahuja, L. (2007). Comparison of modeling approaches to quantify residue architecture effects on soil temperature and water. Soil Tillage Res., 95(1), 84-96. https://doi.org/10.1016/j.still.2006.11.006

Kranner, I., Kastberger, G., Hartbauer, M., \& Pritchard, H. W. (2010). Noninvasive diagnosis of seed viability using infrared thermography. Proc. Natl. Acad. Sci., 107(8), 3912-3917. https://doi.org/10.1073/pnas.0914197107

Lillesand, T., Kiefer, R. W., \& Chipman, J. (2014). Remote sensing and image interpretation. Hoboken, NJ: John Wiley \& Sons.

Mahlein, A.-K., Oerke, E.-C., Steiner, U., \& Dehne, H.-W. (2012). Recent advances in sensing plant diseases for precision crop protection. European J. Plant Pathol., 133(1), 197-209. https://doi.org/10.1007/s10658-011-9878-z

Nugent, P., Shaw, J., \& Pust, N. (2013). Correcting for focal-planearray temperature dependence in microbolometer infrared cameras lacking thermal stabilization. Opt. Eng., 52(6), article 061304. https://doi.org/10.1117/1.OE.52.6.061304

O’Donnell, E. M., Schott, J. R., \& Raqueno, N. G. (2002). Calibration history of Landsat thermal data. Proc. IEEE Intl. Geoscience and Remote Sensing Symp. (Vol. 1, pp. 27-29). Piscataway, NJ: IEEE. https://doi.org/10.1109/IGARSS.2002.1024930

Ortega-Farías, S., Ortega-Salazar, S., Poblete, T., Kilic, A., Allen, R., Poblete-Echeverría, C., \& Sepúlveda, D. (2016). Estimation of energy balance components over a drip-irrigated olive orchard using thermal and multispectral cameras placed on a helicopterbased unmanned aerial vehicle. Remote Sensing, 8(8), article 638. https://doi.org/10.3390/rs8080638

Orżanowski, T. (2016). Nonuniformity correction algorithm with efficient pixel offset estimation for infrared focal plane arrays. SpringerPlus, 5(1), article 1831. https://doi.org/10.1186/s40064016-3534-1

Osroosh, Y., Troy Peters, R., Campbell, C. S., \& Zhang, Q. (2015). Automatic irrigation scheduling of apple trees using theoretical crop water stress index with an innovative dynamic threshold. Comput. Electron. Agric., 118, 193-203. https://doi.org/10.1016/j.compag.2015.09.006

Pen, C. L., Bilanski, W. K., \& Fuzzen, D. R. (1985). Classification analysis of good and bruised peeled apple tissue using optical reflectance. Trans. ASAE, 28(1), 326-330. https://doi.org/10.13031/2013.32251

Perry, D., \& Dereniak, E. (1993). Linear theory of nonuniformity correction in infrared staring sensors. Opt. Eng., 32(8). https://doi.org/10.1117/12.145601

Ribeiro-Gomes, K., Hernández-López, D., Ortega, J. F., Ballesteros, R., Poblete, T., \& Moreno, M. A. (2017). Uncooled thermal camera calibration and optimization of the photogrammetry process for UAV applications in agriculture. Sensors, 17(10), article 2173. https://doi.org/10.3390/s17102173

Schott, J. R., Hook, S. J., Barsi, J. A., Markham, B. L., Miller, J., Padula, F. P., \& Raqueno, N. G. (2012). Thermal infrared radiometric calibration of the entire Landsat 4, 5, and 7 archive (1982-2010). Remote Sens. Environ., 122, 41-49. https://doi.org/10.1016/j.rse.2011.07.022

Scotford, I. M., \& Miller, P. C. (2004). Combination of spectral reflectance and ultrasonic sensing to monitor the growth of winter wheat. Biosyst. Eng., 87(1), 27-38. https://doi.org/10.1016/j.biosystemseng.2003.09.009

Sepúlveda-Reyes, D., Ingram, B., Bardeen, M., Zúñiga, M., OrtegaFarías, S., \& Poblete-Echeverría, C. (2016). Selecting canopy zones and thresholding approaches to assess grapevine water status by using aerial and ground-based thermal imaging. Remote Sensing, 8(10), article 822. https://doi.org/10.3390/rs8100822

Smith, R. C., Barrs, H. D., Steiner, J. L., \& Stapper, M. (1985). Relationship between wheat yield and foliage temperature: Theory and its application to infrared measurements. Agric. Forest Meteorol., 36(2), 129-143. https://doi.org/10.1016/01681923(85)90005-X

Sosnowski, T., Bieszczad, G., Madura, H., Kastek, M., \& Firmanty, K. (2010). The calibration stand for thermal camera module with 
infrared focal plane array. Proc. SPIE 7660: 36th Conf. Infrared Technology and Applications. https://doi.org/10.1117/12.851144

Stajnko, D., Lakota, M., \& Hocevar, M. (2004). Estimation of number and diameter of apple fruits in an orchard during the growing season by thermal imaging. Comput. Electron. Agric., 42(1), 31-42. https://doi.org/10.1016/S0168-1699(03)00086-3

Torres-Rua, A. (2017). Vicarious calibration of sUAS microbolometer temperature imagery for estimation of radiometric land surface temperature. Sensors, 17(7), article 1499. https://doi.org/10.3390/s17071499

Wang, D.-C., Zhang, G.-L., Pan, X.-Z., Zhao, Y.-G., Zhao, M.-S., \& Wang, G.-F. (2012). Mapping soil texture of a plain area using fuzzy-c-means clustering method based on land surface diurnal temperature difference. Pedosphere, 22(3), 394-403. https://doi.org/10.1016/S1002-0160(12)60025-3

Young, S. J., Johnson, B. R., \& Hackwell, J. A. (2002). An in-scene method for atmospheric compensation of thermal hyperspectral data. J. Geophys. Res. Atmos., 107(D24), ACH 14-1 to ACH 1420. https://doi.org/10.1029/2001JD001266

Zhu, Y., Irmak, S., Jhala, A. J., Vuran, M. C., \& Diotto, A. (2019). Time-domain and frequency-domain reflectometry type soil moisture sensor performance and soil temperature effects in fine- and coarse-textured soils. Appl. Eng. Agric., 35(2), 117134. https://doi.org/10.13031/aea.12908 